\title{
Revisiting the Leading Drivers of Pacific Coastal Drought Variability in the Contiguous United States
}

\author{
BENJAMIN I. COOK \\ NASA Goddard Institute for Space Studies, New York, and Division of Ocean and Climate Physics, \\ Lamont-Doherty Earth Observatory, Palisades, New York \\ A. PARK WiLliams \\ Tree Ring Laboratory, Lamont-Doherty Earth Observatory, Palisades, New York \\ JUSTIN S. MANKIN ${ }^{\mathrm{a}}$ \\ NASA Goddard Institute for Space Studies, New York, and Division of Ocean and Climate Physics, \\ Lamont-Doherty Earth Observatory, Palisades, New York \\ Richard SEAGER, JASOn E. SMERdon, AND DeEPTI Singh \\ Division of Ocean and Climate Physics, Lamont-Doherty Earth Observatory, Palisades, New York
}

(Manuscript received 16 March 2017, in final form 28 July 2017)

\begin{abstract}
Coastal droughts that simultaneously affect California, Oregon, and Washington are rare, but they have extensive and severe impacts (e.g., wildfire and agriculture). To better understand these events, historical observations are used to investigate 1) drought variability along the Pacific coast of the contiguous United States and 2) years when extreme drought affects the entire coast. The leading pattern of cold-season (October-March) precipitation variability along the Pacific coast favors spatially coherent moisture anomalies, accounting for $>40 \%$ of the underlying variance, and is forced primarily by internal atmospheric dynamics. This contrasts with a much weaker dipole mode ( $\sim 20 \%$ of precipitation variability) characterized by antiphased moisture anomalies across $40^{\circ} \mathrm{N}$ and strong correlations with tropical Pacific sea surface temperatures (SSTs). Sixteen coastal-wide summer droughts occurred from 1895 to 2016 (clustering in the 1920s-1930s and post-2000), events most strongly linked with the leading precipitation mode and internal atmospheric variability. The frequency of landfalling atmospheric rivers south of $40^{\circ} \mathrm{N}$ is sharply reduced during coastal droughts but not north of this boundary, where their frequency is more strongly influenced by the dipole. The lack of a consistent pattern of SST forcing during coastal droughts suggests little potential for skillful seasonal predictions. However, their tendency to cluster in time and the impact of warming during recent droughts may help inform decadal and longer-term drought risks.
\end{abstract}

\section{Introduction}

In 2015, moderate to exceptional drought covered nearly all of the contiguous United States (CONUS) from Colorado to the Pacific coast (Fuchs 2015). This included the continuation of multiyear events in

\footnotetext{
${ }^{a}$ Additional affiliation: Department of Geography, Dartmouth College, Hanover, New Hampshire.
}

Corresponding author: Benjamin I. Cook, benjamin.i.cook@ nasa.gov
California (Griffin and Anchukaitis 2014; Seager et al. 2015; Williams et al. 2015) and the U.S. Southwest (Delworth et al. 2015; Seager and Hoerling 2014), and the emergence of significant drought conditions across the Pacific Northwest (Oregon and Washington) (Mote et al. 2016). Drought anomalies were especially severe in the three Pacific coastal states (California, Oregon, and Washington).

For California, 2015 ranked as the single worst year of drought on record in terms of 1 April snow water equivalent and August-July unimpaired natural runoff (He et al. 2017). In the Pacific Northwest, record warmth 
drove record low snowpack across Oregon and Washington (Mote et al. 2016). By spring of 2015, drought emergencies were declared in all three of the Pacific CONUS states (Lurie 2015; Wise 2016), conditions that contributed to the worst wildfire year in the United States since modern record keeping began in 1960 (Dickie 2016). Seven of the 10 largest wildfires that year occurred in California and the Pacific Northwest, over 10 million total acres burned across the CONUS and Alaska, and $52 \%$ of the annual U.S. Forest Service budget was spent on wildfire-related expenses (Dickie 2016; Kahn 2016; Roman 2015). The 2015 drought also caused significant agricultural and economic losses, costing California \$2.7 billion and 21000 jobs (Daniels 2016; Rice 2015) and Washington State over $\$ 700$ million (Jenkins 2017).

Extensive coastal droughts that simultaneously affect California and the Pacific Northwest, as occurred in 2015, have often been considered rare relative to other drought patterns. Wise (2016), for example, observed that U.S. West Coast-wide drought events occur less frequently than more regional drought patterns, characterized by out-of-phase moisture anomalies in the meridional direction (e.g., a simultaneously wet Pacific Northwest and dry California). This is likely partly due to the impact of two of the most important climate teleconnections in the western CONUS: El Niño-Southern Oscillation (ENSO) and the Pacific decadal oscillation (PDO). These modes favor out-of-phase precipitation and drought anomalies in the meridional direction that would oppose the development of co-occurring dry (or wet) conditions along the entire CONUS Pacific coast. During cold phases (La Niña and negative PDO), the winter storm tracks that supply most of the moisture to the west are shifted northward, favoring increased precipitation in the Pacific Northwest and reduced precipitation in the southwestern and southern United States (Dettinger et al. 1998; McCabe et al. 2004; Piechota and Dracup 1996; Redmond and Koch 1991). These patterns are reversed during warm phases (El Niño and positive PDO), when the storm tracks are preferentially shifted southward. These dynamics give rise to a "dipole" pattern of antiphased hydroclimate variability that has been documented in precipitation (Brown and Comrie 2004; Dettinger et al. 1998; Wise 2010), streamflow (Meko and Stockton 1984), and other drought indicators (Woodhouse et al. 2009). Along the Pacific coast, the transition latitude between the dipole centers of action, across which moisture anomalies are expected to reverse sign, is $40^{\circ}-42^{\circ} \mathrm{N}$ (e.g., Wise 2010, 2016), separating the Pacific Northwest and Northern California from central and Southern California.

Recently, however, there has been increased interest in understanding factors influencing hydroclimate variability from dynamics outside of the dipole paradigm. This is because teleconnections between North America and ENSOPDO dynamics may lack the strength to overwhelm internal atmospheric variability (Cole and Cook 1998; McAfee 2014; McAfee and Wise 2016), especially during certain seasons when ENSO teleconnections are weaker (e.g., fall and early winter) (Diaz et al. 2001; Jong et al. 2016; McAfee and Wise 2016). It is therefore difficult to rely on these modes alone to develop robust hydroclimate predictions. This was illustrated most recently by the failure of the strong 2015/16 El Niño to bring meaningful drought relief to California and the western CONUS (Kintisch 2016; Wanders et al. 2017).

Further complicating predictions along the Pacific coast are subseasonal dynamics related to atmospheric rivers (ARs), narrow corridors of intense horizontal water vapor transport (Gimeno et al. 2014). The precipitation events associated with the relatively few landfalling ARs every year are disproportionally large contributors to total coldseason precipitation along the Pacific coast (Dettinger 2013; Rutz et al. 2014), especially in California. A small increase or decrease in the number of AR events can thus make the difference between plunging a region into a significant drought (Dettinger et al. 2011) or ending an existing drought (Dettinger 2013). There is little consensus, however, on ENSO-PDO impacts on atmospheric rivers (Gimeno et al. 2014). Dettinger et al. (2011), for example, found that significant correlations between ENSO-PDO and $\mathrm{AR}$ contributions to precipitation along the Pacific coast were confined primarily to Southern California, while other studies suggest ARs may be stronger or more frequent during neutral ENSO phases (Bao et al. 2006; Dettinger 2004).

Other studies have shown that at the monthly to seasonal scale, the leading mode of hydroclimate variability along the Pacific coast is not an ENSO-like dipole but instead a spatially coherent mode that is in phase across the western CONUS. Such a pattern was documented in the early 1980s for precipitation along the Pacific coast (Cayan and Roads 1984; McGuirk 1982), and later for streamflow (Cayan and Peterson 1989; Cayan et al. 2003; Malevich and Woodhouse 2017) and spring snowpack (McCabe and Dettinger 2002). This mode is strongly correlated with extratropical atmospheric circulation anomalies in the North Pacific that occur largely independent of tropical ocean forcing. In wet years on the Pacific coast, low pressure anomalies are centered offshore to the northwest, favoring anomalous cyclonic circulation and southwesterly flow into North America (Klein 1957). During widespread droughts (such as those that occurred in 2015), persistent atmospheric ridging deflects storms away from the entire coast (Cayan and Roads 1984; Seager et al. 2015; Swain et al. 2014, 2016; Wise 2016). 
The relative importance of these various processes and modes of variability will thus have significant consequences for our understanding of drought variability and risk along the CONUS Pacific coast, especially for the most widespread drought events. Here, we revisit the dominant modes of variability in the region to better clarify their importance for hydroclimate and their contribution to the most widespread coastal droughts. We analyze instrumental records of climate over the recent historical period (1895-2016) to investigate the following questions: 1) How strongly do precipitation and drought covary along the CONUS Pacific coast? 2) What is the relative importance of the dipole mode versus coastal-wide mode for drought variability along the Pacific coast? 3) How often do major coastal droughts occur that affect the entire CONUS Pacific coast? 4) What is the relative importance of ocean forcing versus internal atmospheric variability in causing these droughts?

\section{Methods and data}

\section{a. Climate data}

Gridded monthly precipitation totals, mean monthly maximum temperatures, and mean monthly minimum temperatures were accessed from the Gridded Global Historical Climatology Network (GHCN)-Daily Temperature and Precipitation (ClimGrid) dataset produced by the National Oceanic and Atmospheric Administration (Vose et al. 2014). These gridded datasets have $1 / 24^{\circ}$ geographic resolution and cover 1895-2016. ClimGrid temperatures were calibrated to the gridded version 1.2.0 Topography Weather (TopoWx) temperature dataset (Oyler et al. 2015) such that the two datasets agreed in terms of monthly means and standard deviations during 1961-2010 (e.g., Williams et al. 2015). TopoWx better represents temperature at higher elevations in the western United States (Oyler et al. 2015) but does not cover the entire period of study. For drought calculations, atmospheric evaporative demand was represented as the Penman-Monteith reference evapotranspiration (Monteith 1965), which is a model estimate of evapotranspiration from an idealized crop when water is not limiting. Monthly input variables are temperature, vapor pressure, wind speed, and solar radiation. Vapor pressure was calculated from monthly $1 / 24^{\circ}$ grids of mean dewpoint from the PRISM group at Oregon State University (Daly et al. 2008). Wind speed was calculated at $2 \mathrm{~m}$ above the surface and net downward solar radiation at the surface, compiled from multiple sources. The North American Land Data Assimilation System, version 2 (NLDAS2; Mitchell et al.
2004), data were used for 1979-2016 and were extended back to 1948 by calibrating data from the Global Land Data Assimilation System (GLDAS; Rodell et al. 2004) to NLDAS2 for the overlapping period of 1979-2010. We refer to the resultant dataset as LDAS. The LDAS records were extended back to 1901 using the Princeton Global Forcing (PGF) dataset (available from 1901 to 2014; Sheffield et al. 2006), calibrated to LDAS during 1961-2010. Because the PGF dataset begins in 1901, we held wind speed and solar radiation to their monthly means for 1895-1900. For vapor pressure, wind speed, and solar radiation, each dataset has a different geographic resolution and all records were bilinearly interpolated to a common resolution of $1 / 4^{\circ}$. The LDAS dataset represents wind speeds at $10 \mathrm{~m}$ above the surface, so we applied a logarithmic wind profile following Allen et al. (1998) to estimate wind speed at $2 \mathrm{~m}$. Downward solar radiation values were converted to net solar radiation values by applying the mean monthly NLDAS2 albedo climatology for 1979-2010 (our assumption of no interannual variability in albedo was found to have negligible impacts on drought calculations in exploratory analysis). Finally, precipitation and temperature grids were aggregated to a $1 / 4^{\circ}$ geographic resolution for calculations of reference evapotranspiration and drought.

To define summer drought, we use summer season [June-August (JJA)] average values of the selfcalibrating Palmer drought severity index (PDSI; Palmer 1965; Wells et al. 2004) calculated from these instrumental datasets. PDSI is a normalized index of drought (soil moisture) that integrates changes in supply (precipitation) and demand (evapotranspiration) over multiple seasons, therefore making it an appropriate index for analyzing drought even over regions where moisture supply is dominated by cold-season precipitation (e.g., the Pacific coast of North America). Negative (positive) values indicate dry (wet) conditions relative to a baseline average of zero (values of -1 are considered a "moderate" drought). PDSI is widely used in observational analyses (Trenberth et al. 2014), as a target for tree-ring-based paleoclimate reconstructions (Cook et al. 2004) and to investigate drought dynamics in model simulations (Coats et al. 2015; Cook et al. 2014, 2015; Dai 2013; Feng et al. 2017). Drought variability in PDSI compares favorably with soil moisture from more sophisticated land surface models (Cook et al. 2015; Feng et al. 2017), even in regions strongly dominated by snow (a process not explicitly simulated in the PDSI calculations), such as the Sierra Nevada (e.g., Williams et al. 2015).

The climate datasets and PDSI used here were developed previously for a study investigating climate 
change contributions to the recent California drought (Williams et al. 2015). As part of that study, these data were compared against alternative datasets, and their variability, trends, and effects on PDSI calculations were also extensively assessed. The ClimGrid temperature and precipitation closely track the variability and trends of data from other sources (e.g., precipitation from the Global Precipitation Climatology Centre and temperature from the Berkeley Earth Surface Temperature project). Calculations of atmospheric moisture demand (potential evapotranspiration) and PDSI across these different temperature and precipitation datasets yielded near-identical results across the entire period of record (Figs. 1a,c,h in Williams et al. 2015). The largest uncertainties are likely in the estimates of potential evapotranspiration derived from humidity, wind speed, and solar radiation, which differ substantially between datasets, especially prior to 1950 (Figs. 1e-g in Williams et al. 2015). Despite these differences, Williams et al. (2015) show that humidity, wind speed, and solar radiation are far less important than precipitation and temperature in terms of driving PDSI variability and trends in California, and we find this to be true throughout our U.S. West Coast study region. Importantly, uncertainty may also be introduced through our method of temporally extending the wind speed and solar radiation data, because combining two datasets with differing spatial resolutions, even if calibrated temporally, may still influence temporal variability in regionally averaged time series. The minimal contribution of wind speed and solar radiation to interannual PDSI variability in our study region dictates that any artificial shifts in temporal variability in wind speed or solar radiation are essentially inconsequential for PDSI. All other analyses of Pacific coast surface climate that do not involve PDSI focus on the much higher-quality and more temporally homogeneous temperature and precipitation data from ClimGrid. Further details and evaluations of these datasets are provided in Williams et al. (2015) and their associated supplemental material.

To investigate the robustness of various modes of precipitation variability, we also use version 7 of the Global Precipitation Climatology Centre (GPCC) precipitation dataset (Schneider et al. 2014, 2015). GPCC is a global gridded dataset of monthly precipitation totals interpolated from land surface stations at $1 / 2^{\circ}$ spatial resolution (available from 1901 to 2013). To understand the dynamics underlying precipitation variability and coastal droughts along the Pacific coast, we use the 200-hPa monthly geopotential height fields from version $2 \mathrm{c}$ of the Twentieth Century Reanalysis (available from 1851 to 2014; Compo et al. 2011). To analyze possible sea surface temperature (SST) forcing and the influence of ENSO, we use the Hadley Centre Sea Ice and SST dataset [HadISST (1870-present); Rayner et al. 2003] and the monthly PDO index dataset (1854-present) from NOAA/National Centers for Environmental Information (https://www.ncdc.noaa.gov/teleconnections/ $\mathrm{pdo} /$ ). We also consider the potential influence of the tropical Atlantic by analyzing the Atlantic multidecadal oscillation (AMO) index from the NOAA/Earth System Research Laboratory (http://www.esrl.noaa.gov/psd/ data/timeseries/AMO/; Enfield et al. 2001). Finally, we investigate the connection between coastal droughts, precipitation variability, and ARs by analyzing the AR dataset of Guan and Waliser (2015). This dataset includes information on the location of landfalling ARs calculated from the NCEP-NCAR reanalysis (19482015) at 6-hourly resolution. From this dataset, we compiled a list of the number of AR landfalling days during each cold season (October-March) in each of our Pacific coastal regions (described below).

\section{b. Analyses}

We focus on the CONUS Pacific coast $\left(32^{\circ}-50^{\circ} \mathrm{N}\right.$, $\left.126^{\circ}-116^{\circ} \mathrm{W}\right)$, further subdividing this area into southern $\left(32^{\circ}-40^{\circ} \mathrm{N}, 126^{\circ}-116^{\circ} \mathrm{W}\right)$ and northern $\left(40^{\circ}-50^{\circ} \mathrm{N}, 126^{\circ}-\right.$ $116^{\circ} \mathrm{W}$ ) coastal regions. This division along $40^{\circ} \mathrm{N}$ latitude corresponds with the rough climatological latitude for the storm track and the long-term average boundary between the northern and southern ends of what has been defined as the moisture dipole (Dettinger et al. 1998; Wise 2010, 2016). We apply the following criteria to define widespread drought years during the summer season: 1$)$ PDSI $\leq-1$ over at least $70 \%$ of the entire coastal region $\left(32^{\circ}-50^{\circ} \mathrm{N}, 126^{\circ}-116^{\circ} \mathrm{W}\right.$,) and 2$)$ area average PDSI $\leq-1$ in both the northern and southern coastal regions. These criteria are designed to identify the most extensive and intensive coastal drought events and to position us to evaluate their characteristics and causes. All climate anomalies are calculated relative to a 1921-2000 baseline, and the JJA PDSI is recentered to have a zero mean over this same period. All correlations (Spearman's rank) are calculated using linearly detrended data to avoid artificially amplified correlations due to co-occurring, but potentially unrelated, trends.

\section{Results and discussion}

\section{a. Precipitation seasonality and summer drought (PDSI)}

Most precipitation in the southern and northern coastal regions occurs during the cold season from November through April (Fig. 1, top). Northern coast precipitation peaks in November and December, with a 
Water-Year Precipitation (mm/day)

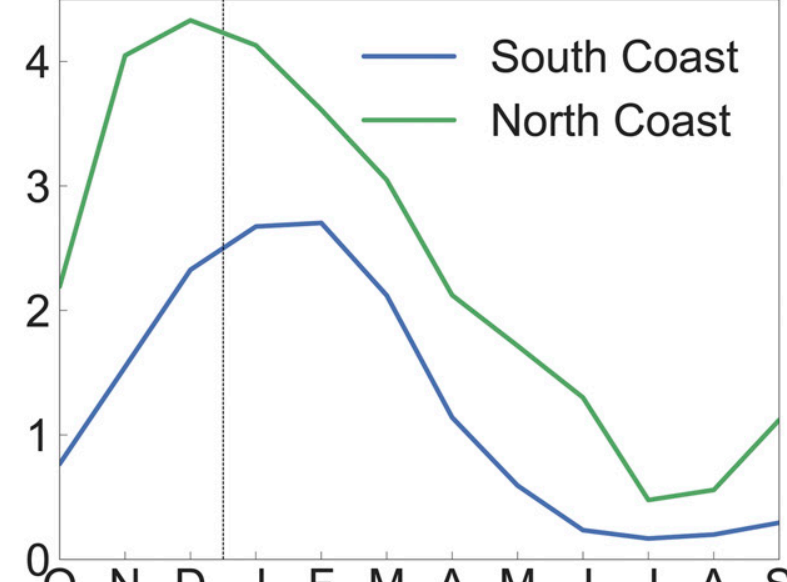

O
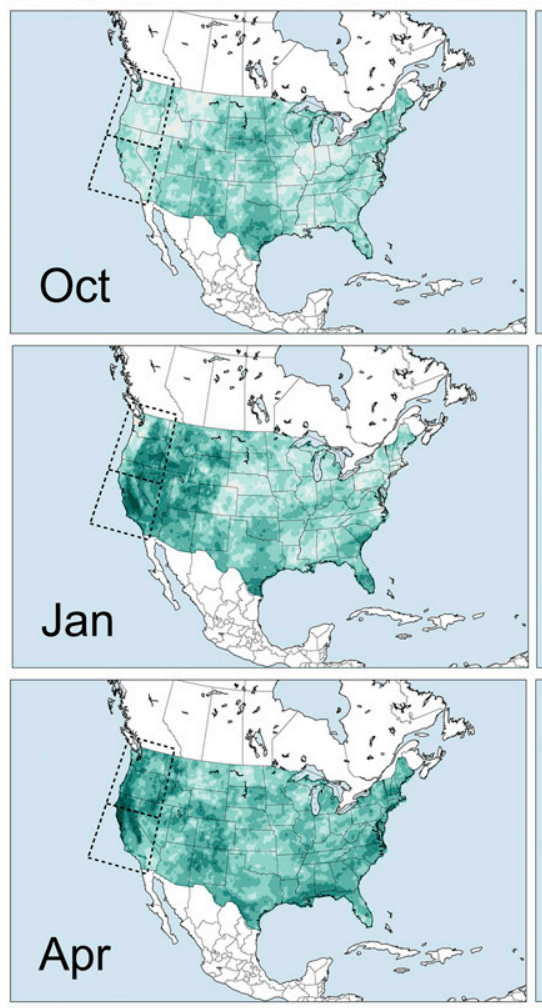

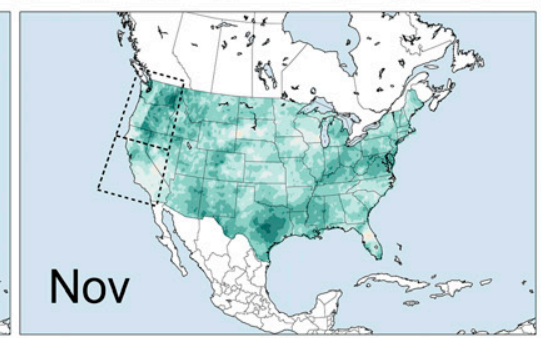

Dec

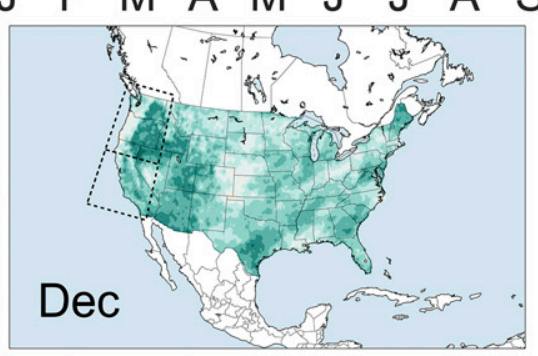

Feb
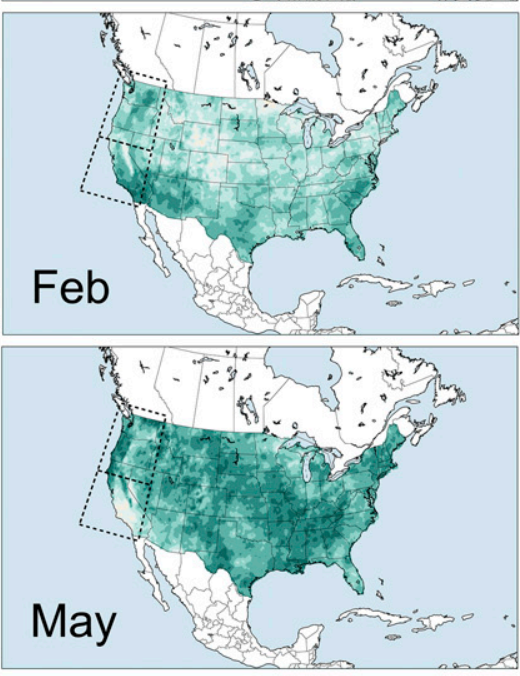
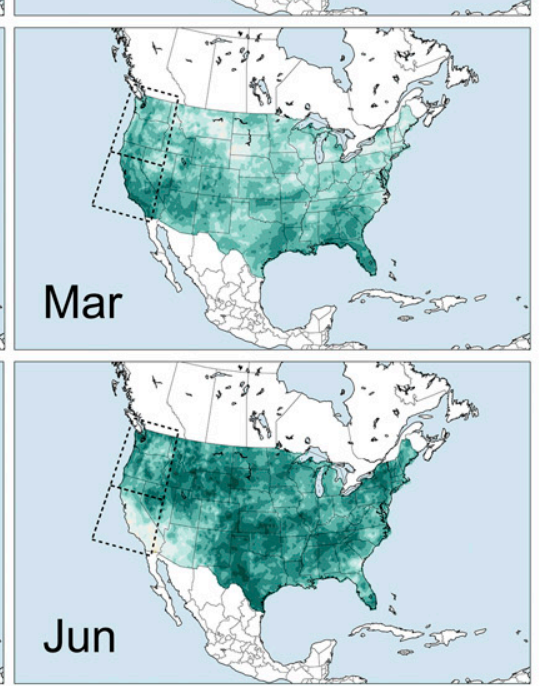

\section{$\begin{array}{lllllllllllllll}-0.7 & -0.6 & -0.5 & -0.4 & -0.3 & -0.2 & -0.1 & 0.0 & 0.1 & 0.2 & 0.3 & 0.4 & 0.5 & 0.6 & 0.7\end{array}$ Correlation, Monthly Precipitation vs JJA PDSI}

FIG. 1. (top) Long-term (1896-2016) (left) mean and (right) fraction of water-year total precipitation for October through September precipitation over the southern $\left(32^{\circ}-40^{\circ} \mathrm{N}, 126^{\circ}-116^{\circ} \mathrm{W}\right)$ and northern $\left(40^{\circ}-50^{\circ} \mathrm{N}, 126^{\circ}-116^{\circ} \mathrm{W}\right)$ coasts. (bottom) Correlations between summer average (JJA) self-calibrating PDSI and antecedent or concurrent monthly precipitation in the ClimGrid dataset. OND precipitation fields are taken from the preceding year of the JJA PDSI. The northern and southern coastal regions are indicated by the black dashed boxes.

substantial fraction of the seasonal total extending into the early and late spring (April-June). Seasonality is more extreme, and total precipitation is lower, in the southern coastal region, peaking in January and
February with very little occurring after April. Point-topoint correlations between monthly precipitation and JJA PDSI highlight the importance of cold-season precipitation to summer drought on the CONUS Pacific 

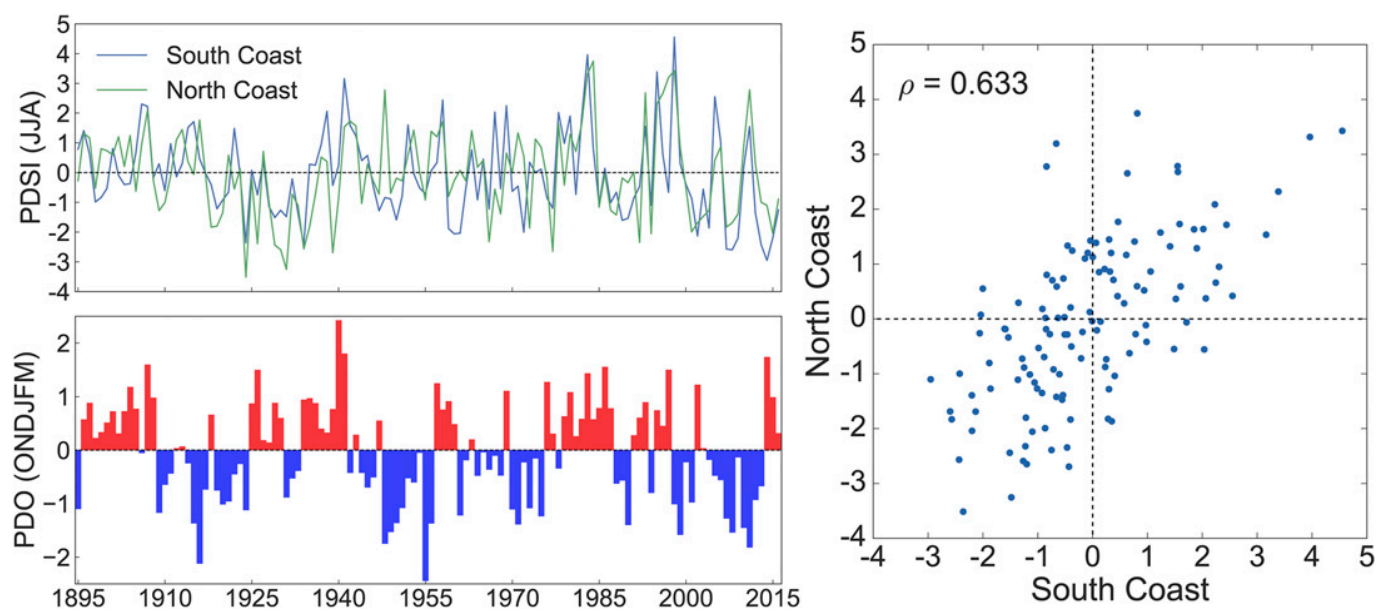

FIG. 2. (top left) Regional average summer (JJA) self-calibrating PDSI from the northern and southern coasts for 1895-2016. (right) PDSI variability between the two regions is strongly and significantly positively correlated ( $\rho=$ $0.633, p \leq 0.001$ ), indicating a tendency for in-phase summer moisture anomalies across the two regions. (bottom left) The ONDJFM average PDO index is also shown, highlighting the lack of coherence between PDO phasing and coastal drought variability.

coast (Fig. 1, bottom). Over the northern coast, the strongest correlations with summer PDSI are from November to June, while over the southern coast the largest contribution to summer soil moisture comes from precipitation during December-April.

\section{b. Northern and southern coast precipitation and drought variability}

Since the late nineteenth century, drought variability (PDSI) between the northern and southern coasts has been significantly $(p<0.001)$ and positively correlated ( $\rho=0.633$; Fig. 2$)$, with apparent in-phase coherence at longer time scales. The latter includes periods of persistent cross-region dryness during the 1920s, 1930s, 1980s, and early twenty-first century, with anomalous wetness at the turn of the twentieth century and in the 1990s. This pancoastal decadal variability is impressive, since it is not a simple result of the PDO, which typically causes opposite-sign anomalies in winter precipitation over the northern and southern coasts (e.g., McCabe et al. 2004). Furthermore, there is little consistency in PDO state across decades of coherent coastal dryness. For example, the October-March (ONDJFM) PDO was weakly positive during the 1920 s $(+0.14)$, more strongly positive during the 1930s $(+0.49)$, but negative during the post-2000 period $(-0.35)$.

This strong covariability is also found in cool-season precipitation, which shows similarly significant $(p<$ 0.001) positive correlations (Fig. 3) between the northern and southern coasts. The strongest precipitation correlations occur in October-December (OND) and April-May, and are weaker but still significant during
January-March (JFM). Precipitation anomalies in both regions may therefore share similar dynamical origins, as indicated by previous studies demonstrating that high precipitation across the entire Pacific coast is associated with low pressure and convergence in the region (Cayan and Roads 1984; Klein 1957). This can be seen in the strong negative correlations between northern and southern coast precipitation and the $200-\mathrm{hPa}$ geopotential heights over the ocean and offshore of the coast (Fig. 4), circulation anomalies that would favor enhanced precipitation along the CONUS Pacific coast. In October-December and January-March, the height anomalies resemble internal atmospheric variability, but in April-May there is an apparent connection to tropical Pacific height anomalies that is likely SST forced, consistent with the winter-spring intensification of ENSO teleconnections over North America (Jong et al. 2016; McAfee and Wise 2016).

To further clarify contributions of the dipole mode to hydroclimate variability, we conduct a principal component analysis (PCA) on October-March (1902-2013; the overlapping period between the two datasets) precipitation from ClimGrid and GPCC over our restricted Pacific coastal domain and (for GPCC only) a much expanded region of western North America $\left(21^{\circ}-60^{\circ} \mathrm{N}\right.$, $135^{\circ}-112^{\circ} \mathrm{W}$ ). Over the Pacific coastal region (Fig. 5, left and center), the leading unrotated empirical orthogonal function (EOF) in both ClimGrid and GPCC has a uniform sign across the domain and accounts for $>40 \%$ of the underlying variance. By contrast, the dipole mode, characterized by opposite-sign anomalies in the northern and southern coastal regions, appears as the 


\section{Seasonal Precipitation (mm/day)}
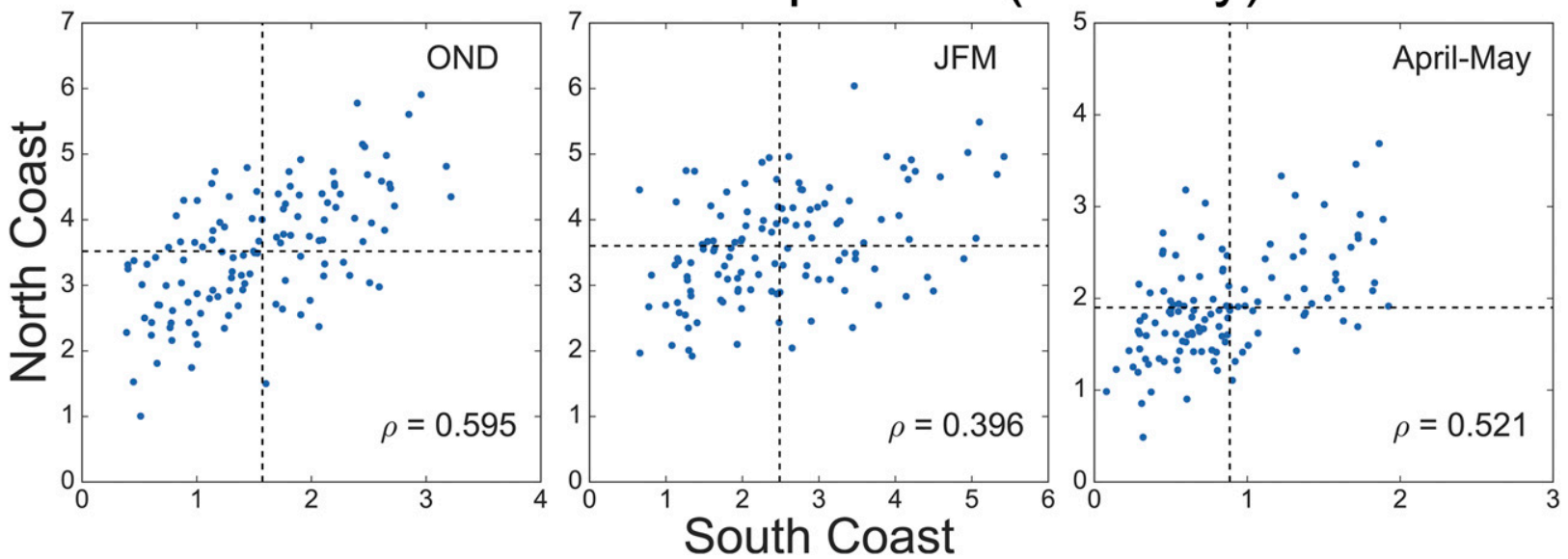

FIG. 3. Regional average precipitation $\left(\mathrm{mm} \mathrm{day}^{-1}\right)$ comparisons between the northern and southern coastal regions for the (left) fall and early winter (OND), (center) winter and early spring (JFM), and (right) spring (April-May). Mean precipitation for each region and season, calculated from our baseline period (1921-2000), are indicated with black dashed lines.

second EOF, accounting for $\sim 20 \%$ of the total precipitation variance. Only when the analysis domain is expanded over a much broader region (Fig. 5, right) does a quasi-dipole-like mode emerge as the leading pattern, with the CONUS west-wide mode as the second EOF (EOF2), but with neither mode emerging as substantially dominant over the other. Furthermore, the main centers of action in the leading dipole mode in this example are centered in the Pacific Northwest and southwestern United States, not the

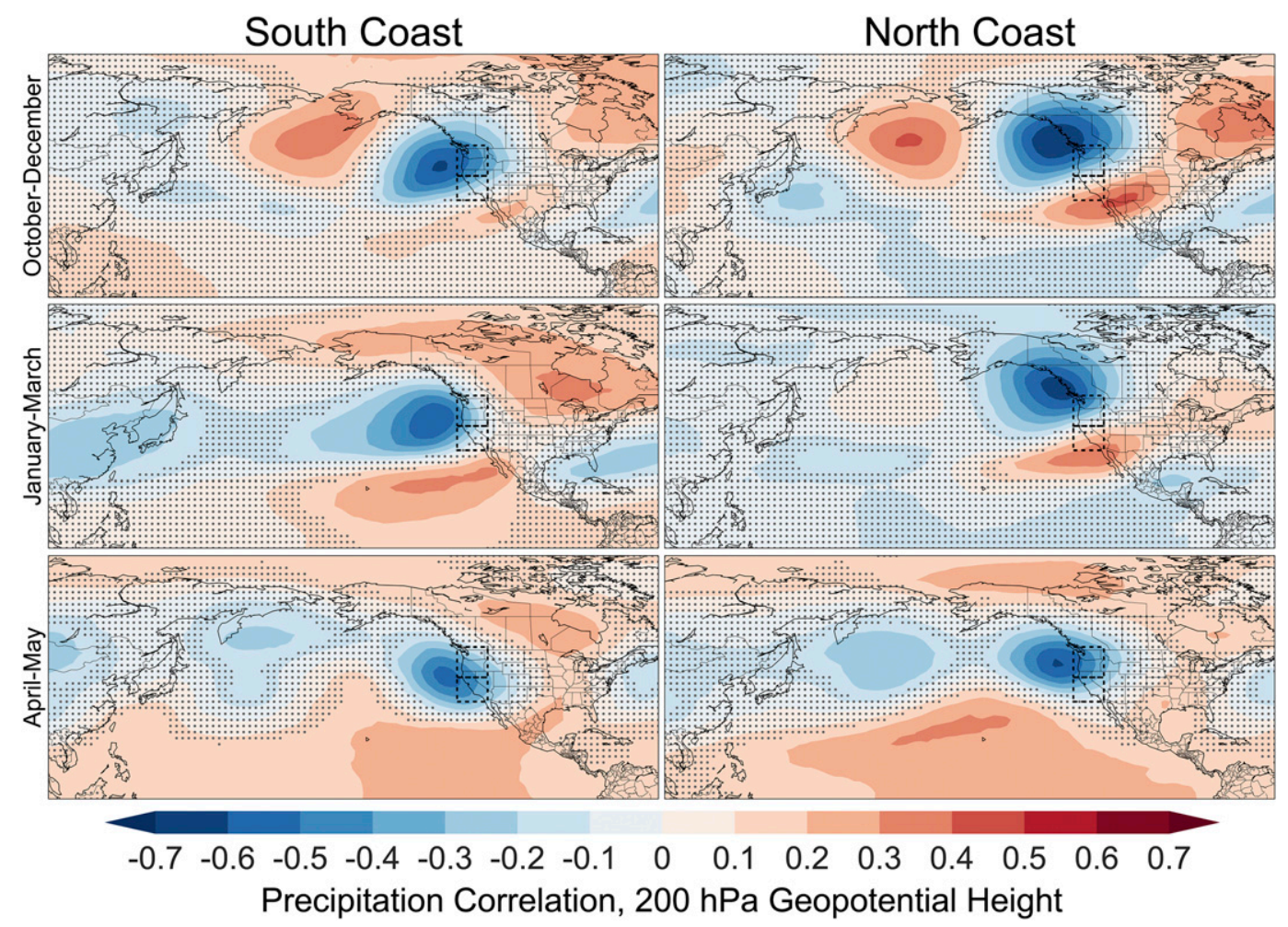

FIG. 4. Correlations between average precipitation for the (left) southern and (right) northern coasts, and 200-hPa geopotential height anomalies for different seasonal windows: (top) OND, (middle) JFM, and (bottom) April-May. Areas of negative correlation (blue) indicate low pressure anomalies associated with high precipitation in the southern or northern coastal region. Insignificant correlations $(p>0.10)$ are stippled in gray. 


\section{Leading Modes, ONDJFM Precipitation}

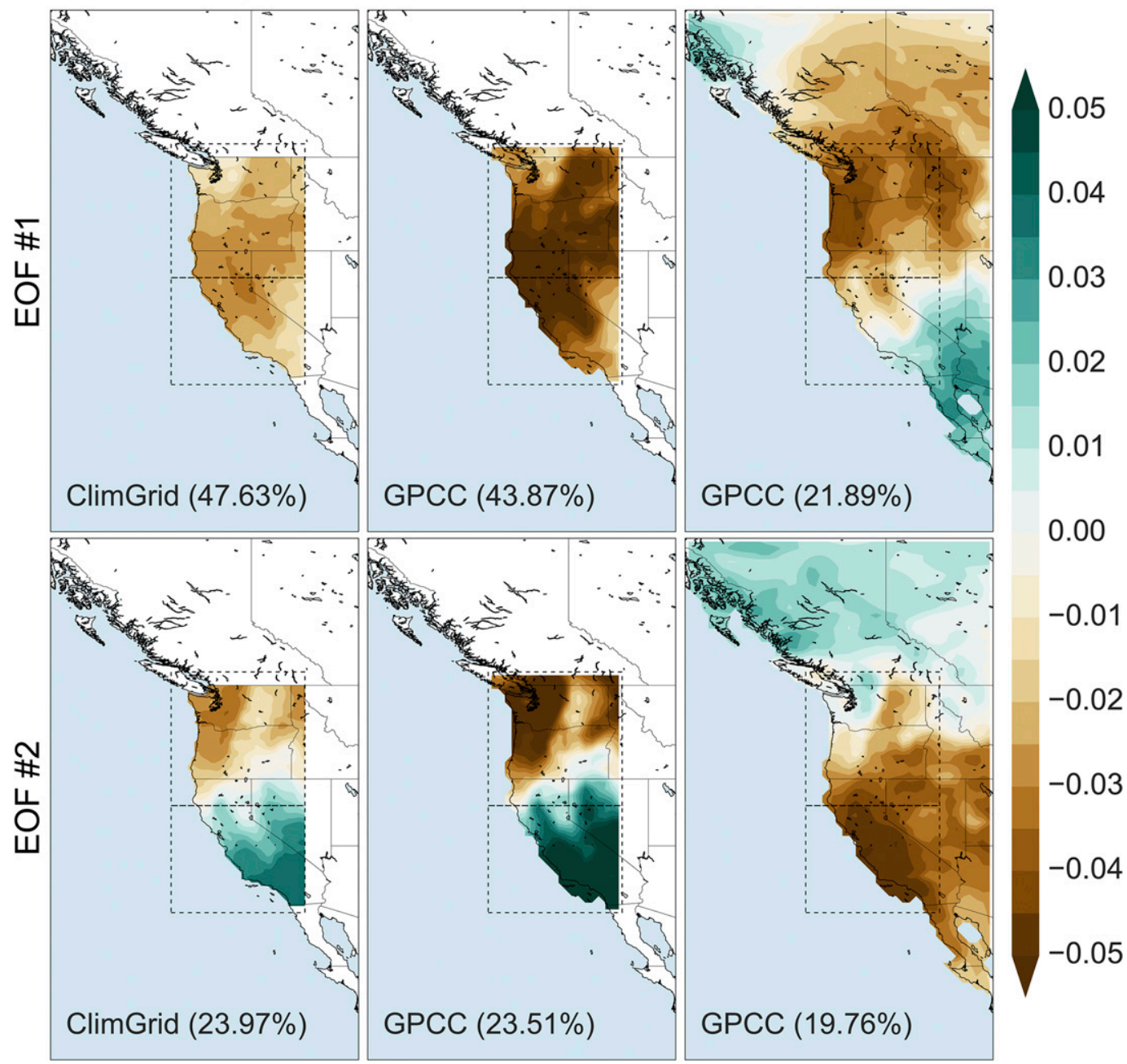

FIG. 5. Two leading unrotated EOFs from a PCA of cold-season (ONDJFM) precipitation in the (left) ClimGrid and (center),(right) GPCC datasets from 1902 to 2013 (the overlapping period between ClimGrid and GPCC). In (left),(center), the analysis domain is restricted to the combined northern and southern coastal regions. In (right), the domain is expanded over the much larger region of western North America $\left(21^{\circ}-60^{\circ} \mathrm{N}, 135^{\circ}-112^{\circ} \mathrm{W}\right)$. Inset numbers indicate the percent of total ONDJFM precipitation variance represented by each mode.

northern and southern coastal regions separated at $40^{\circ}-42^{\circ} \mathrm{N}$

These results are supported by additional analyses (Fig. 6) in which we conduct point-by-point correlations between October-March precipitation from four cities along the Pacific coast and GPCC precipitation across western North America. For all four cities, correlations along the CONUS Pacific coast are mostly of the same sign, with a spatial pattern similar to the leading EOF from the restricted coastal EOF analyses. Dipole-like patterns do emerge, but with opposing centers of action in British Columbia and the CONUS Pacific coast (similar to EOF2 from the GPCC analysis over the expanded domain). As before, there is little evidence for a dominant dipole pattern along the CONUS Pacific coast across $40^{\circ}-42^{\circ} \mathrm{N}$.

\section{c. Coastal droughts}

We identified 16 coastal droughts ( $\sim 13 \%$ of the years) from 1895 to 2016 (brown dots in Fig. 7, top; individual years listed in the caption). Using a $50 \%$ (rather than $70 \%$ ) drought area threshold resulted in only four more years qualifying as coastal droughts (1928, 1933, 1985, and 1987). Over the entire period of record, there is no apparent trend in either occurrence or intensity of these events, though they are unevenly distributed in time, with clusters during persistent periods of co-occurring 


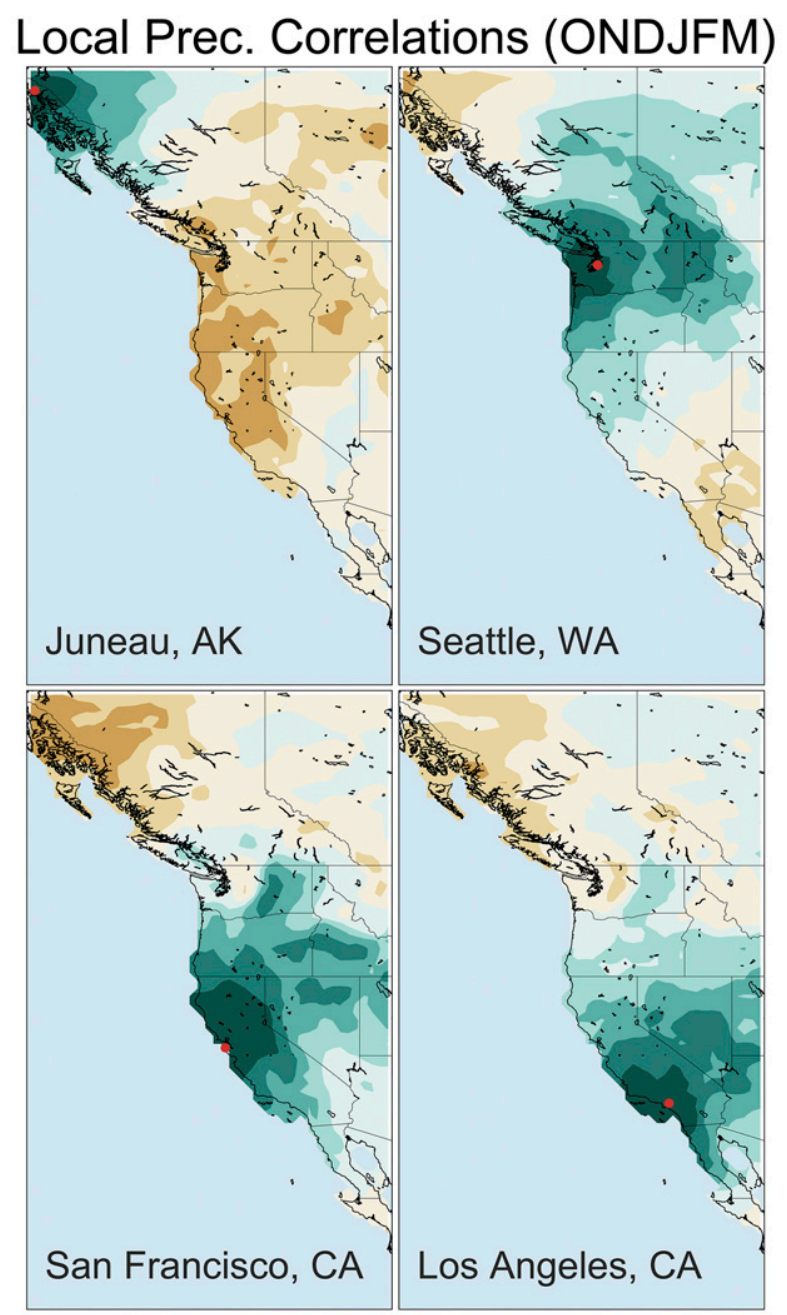

$\begin{array}{lllllllllll}-1.0 & -0.8 & -0.6 & -0.4 & -0.2 & 0.0 & 0.2 & 0.4 & 0.6 & 0.8 & 1.0\end{array}$

FIG. 6. Point-by-point correlations between GPCC cold-season (ONDJFM) precipitation and precipitation from four U.S. West Coast cities: Juneau, Alaska; Seattle, Washington; San Francisco, California; and Los Angeles, California. City precipitation was calculated by averaging precipitation in all grid cells within $1^{\circ}$ latitude/ longitude of the approximate city location (red dot in each panel).

dryness in the northern and southern coastal regions (see Fig. 2). The first cluster is during the 1920s and 1930 s, a period of some of the worst drought years in California (Mirchi et al. 2013) and the worst multiyear drought in United States history (the Dust Bowl; Schubert et al. 2004). The second major cluster occurred post-2000, coincidentally during a period of persistent La Niña-like conditions in the tropical Pacific likely responsible for drought conditions across much of western North America (Delworth et al. 2015; Seager and Vecchi 2010).

Composite maps of PDSI (median) during coastal drought years confirm that these events are spatially coherent and associated with expansive drought across much of the western CONUS (Fig. 7, bottom). Anomalies in some regions weaken or reverse in the composite for the post-2000 period, when the dominance of a cold tropical Pacific forcing shifted the post-2000 baseline climate to more closely reflect a La Niña-like pattern. This caused anomalous dryness (U.S. Southwest, Texas, and U.S. Southeast) and wetness (the Great Plains and Midwest) that acted to oppose the regional anomalies associated with coastal droughts in the pre-2000 composite, suggesting there is little evidence that $\mathrm{La}$ Niña-like states contribute to the clustering of coastal droughts-something we confirm in later analyses.

\section{d. Precipitation and temperature anomalies during coastal droughts}

October through May precipitation anomalies (median calculated across the 16-yr drought composite) are negative along the entire Pacific coast during winters preceding coastal droughts (Fig. 8, left). Area-averaged anomalies in the drought composite are $29.2 \%$ and $16.8 \%$ below normal in the southern and northern coastal regions, respectively. There is little consistency, however, in the timing of the most significant prior coolseason precipitation deficits during individual drought events (not shown). In 2014, for example, the largest precipitation deficits in both regions occurred relatively early in the cold season (October-January). This contrasts sharply with 1934, when the largest deficits occurred after February.

Anomalous warmth extends across the same region during the droughts (median, calculated across the 16-yr drought composite), with the strongest anomalies occurring in maximum temperatures (Fig. 8, center and right). While anomalous spring-summer warmth in these years can contribute to increasing drought severity through impacts on snow cover and evaporative demand (e.g., Berg and Hall 2017; Williams et al. 2015; Mote et al. 2016), precipitation deficits are the primary driver of historical drought variability in this region (e.g., Seager et al. 2015; Williams et al. 2015). Some of this warmth, therefore, also likely represents a response to, rather than cause of, these droughts through various mechanisms, which include reduced evaporative cooling from dry soils (Seneviratne et al. 2010), increased surface insolation from lower cloud cover (Wolf et al. 2017; Yin et al. 2014), and the influence of the blocking ridge in the atmosphere (Singh et al. 2016; Wang et al. 2015).

\section{e. Circulation and ocean forcing of coastal droughts}

The coastal PDSI time series is significantly and negatively correlated with the first principal component (PC1) of the ClimGrid data, the coastal-wide prior 

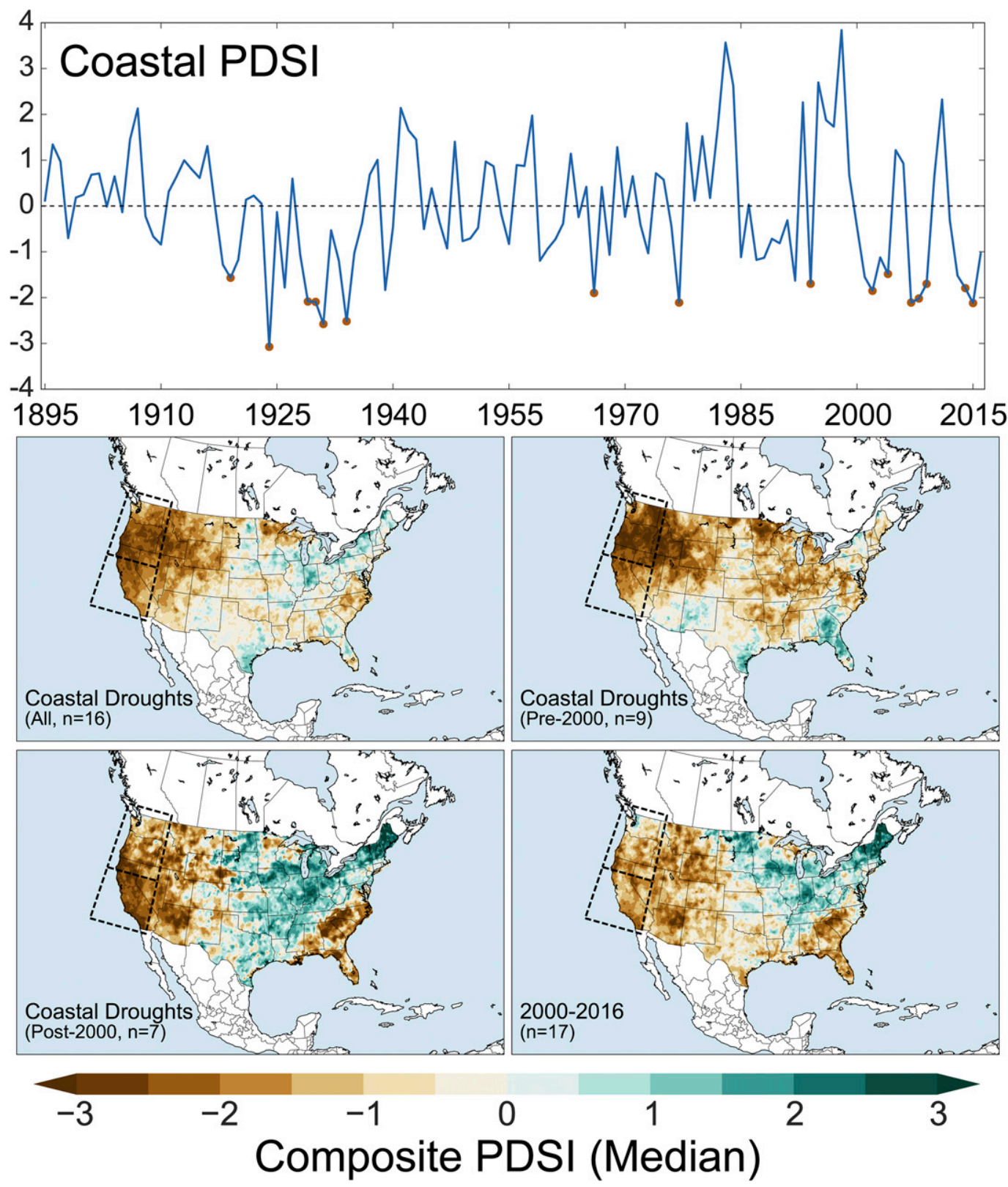

FIG. 7. (top) Area-averaged PDSI for the combined northern and southern coastal regions. Average or normal conditions (zero mean for the 1921-2000 baseline) are indicated by the dashed lines. The 16 coastal drought events identified in our study are marked with brown dots $(1919,1924,1929,1930,1931,1934,1966,1977,1994,2002$, 2004, 2007, 2008, 2009, 2014, and 2015). (bottom) Composite summer PDSI (median) for all coastal drought years $(n=16)$, coastal drought years before $2000(n=9)$, coastal drought years after $2000(n=7)$, and PDSI for 2000-16 $(n=17)$.

winter precipitation mode (Fig. 9, left). Note that because of the sign conventions on the PC and EOF, a positive value of $\mathrm{PC} 1$ is associated with negative precipitation anomalies across the CONUS Pacific coast. Positive values of this mode occur in nearly all coastal droughts (highlighted in brown), consistent with the associated EOF loading and spatially coherent negative precipitation anomalies that characterize these events. The correlation between coastal PDSI and the dipole mode, represented by PC2, is weak and insignificant (Fig. 9, right), with coastal droughts occurring during both positive and negative phases of this mode. There are no long-term significant trends in either PC, although PC1 is biased positive during the drought 


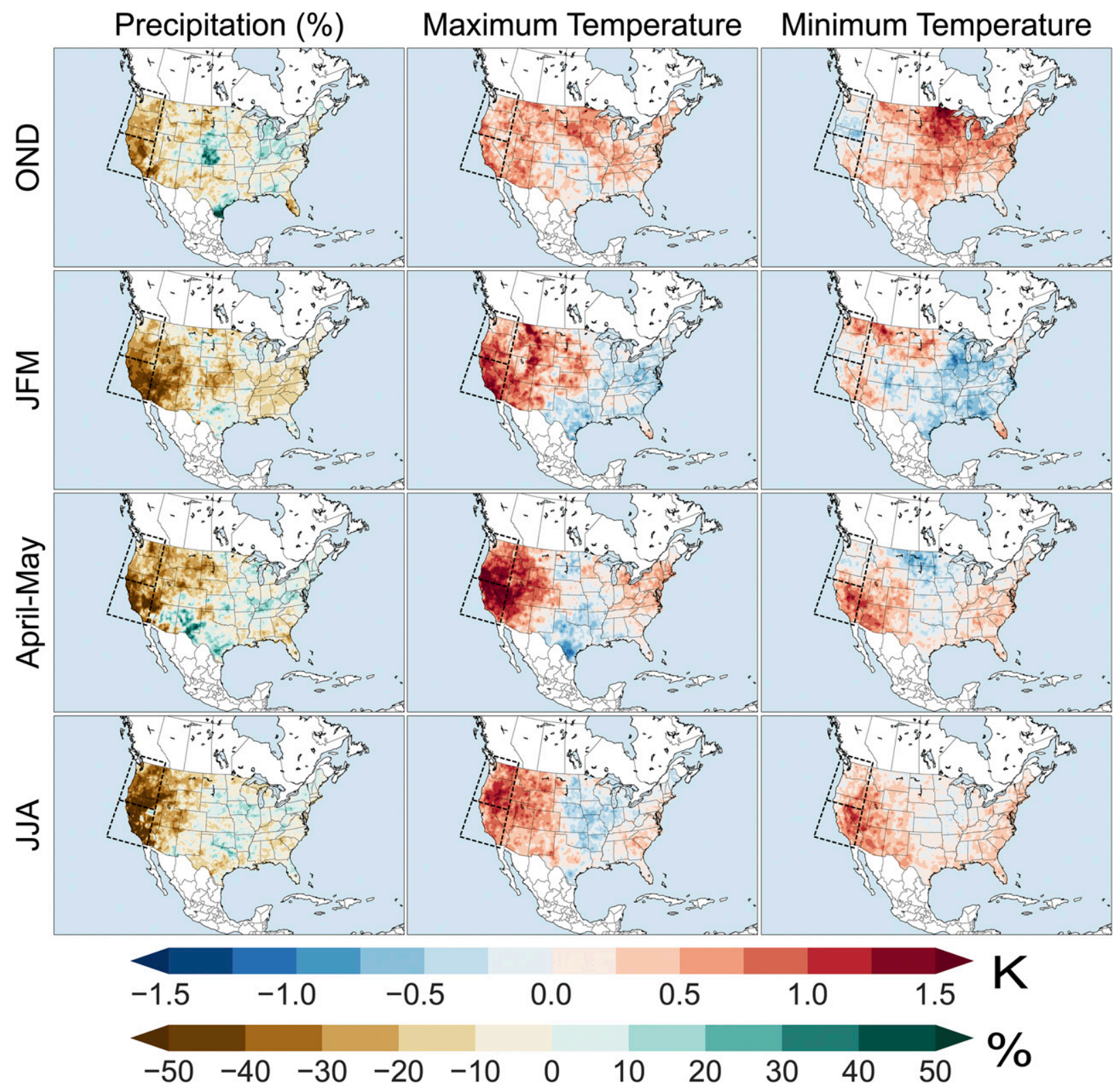

FIG. 8. Composite (median) precipitation (percent of normal) and maximum and minimum temperature (K) anomalies in the ClimGrid dataset during the 16 coastal drought years for fall and early winter (OND), winter and early spring (JFM), April-May, and summer (JJA). All anomalies are calculated relative to the average from the 105 nondrought years.

clusters in the 1920s-1930s and early twenty-first century (not shown).

PC1 and the coastal PDSI time series have similar correlation patterns with $200-\mathrm{hPa}$ height anomalies, especially along the west coast of North America (Fig. 10, left). In both cases they reflect the association between wet years and anomalous low pressure off the Pacific coast and high pressure across the southwestern United States (similar to Fig. 4). These patterns contrast sharply with the precipitation dipole in PC2, which is associated with negative heights over the midlatitudes and anomalous high pressure in the tropics and over northwestern North America. PC1 and the coastal PDSI are only weakly correlated with SSTs (Fig. 10, right), with the most significant correlations over the extratropical North Pacific and Atlantic. This extratropical SST signal in the Pacific most likely reflects the atmosphere forcing the ocean or shifts in the extratropical ocean related to tropical Pacific variability (Bond et al. 2015; Davis 1976; Hartmann 2015), rather than the forcing of the 

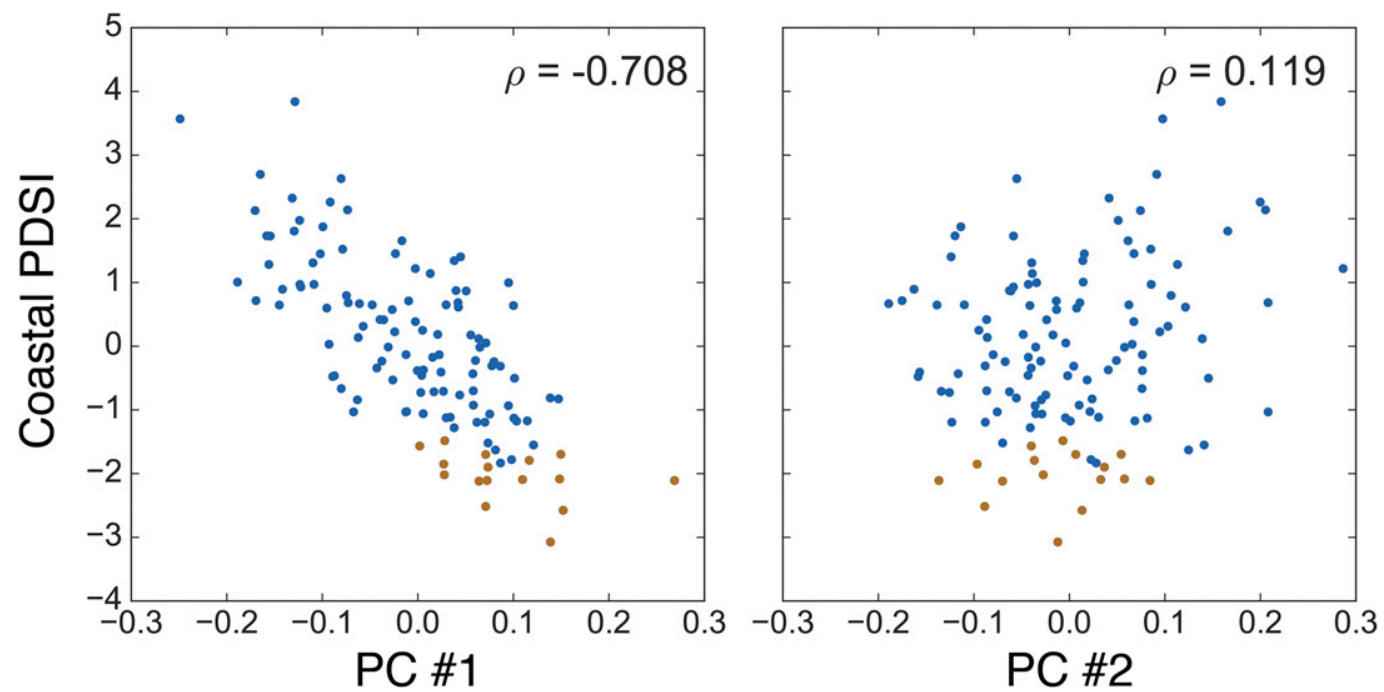

FIG. 9. Comparisons (1896-2016) between the coastal average PDSI and PC1 and PC2 from the EOF analysis of October-March ClimGrid precipitation. For this, and subsequent analyses, the EOF analysis was expanded from 2013 through 2016 in order to capture all the coastal droughts. Spearman's rank correlation is shown in the top-right corners, and coastal drought years are indicated with brown dots.

atmosphere by the extratropical ocean. However, there is some evidence that such extratropical SST patterns may act as feedbacks to reinforce the coincident atmospheric ridge (Lee et al. 2015; Swain et al. 2016; Wang et al. 2017). Relative to PC1, however, PC2 is much more strongly related to ocean variability, including widespread positive correlations with SSTs in the tropical Pacific and Indian Oceans, reflecting the connection to ENSO and PDO variability (e.g., Brown and Comrie 2004; Wise 2010).

The lack of strong correlations between the coastal PDSI time series and either SSTs or the dipole precipitation mode indicates that coastal droughts are most closely linked to internal atmospheric variability, with little to no influence from the ocean. As noted previously, there is little consistency in the seasonal timing of precipitation deficits across droughts, and this dissimilarity extends to the $200-\mathrm{hPa}$ geopotential height and SST anomalies for the extended cold season (October-May) (Fig. 11). Coastal droughts occurred during major El Niño (e.g., 1919, 1931, 1966, and 1977) and La Niña events (e.g., 1934 and 2008), and even in the atmosphere there is wide diversity in seasonal average circulation patterns that have occurred. The droughts in 1930 and 1934, for example, had strong anomalous ridging centered right along the CONUS west coast, while in other years the high was centered over the ocean (e.g., 2008 and 2009) or at higher latitudes over North America (e.g., 1919 and 1977).

To quantify the inconsistency in ocean-atmosphere dynamics, we calculated uncentered Spearman's rank pattern correlations between each possible pair of coastal drought years for tropical Pacific SSTs $\left(20^{\circ} \mathrm{S}-\right.$ $20^{\circ} \mathrm{N}, 140^{\circ} \mathrm{E}-70^{\circ} \mathrm{W} ; n=5600$ grid points) and North Pacific 200-hPa geopotential height anomalies $\left(20^{\circ}-\right.$ $70^{\circ} \mathrm{N}, 170^{\circ}-100^{\circ} \mathrm{W} ; n=936$ grid points) for the October-May period. These correlations provide a simple indicator of the level of similarity in the spatial patterns of these anomalies across all events. High positive correlations indicate strong similarity in the spatial pattern of anomalies between two events; strong negative correlations indicate strongly inverted anomaly fields.

Across all possible pairwise comparisons (Fig. 12; 119 for geopotential heights and 120 for SSTs), most correlations are relatively weak $(-0.4 \leq \rho \leq+0.4 ; 74$ for SSTs and 88 for geopotential heights), indicating diversity in circulation patterns in the ocean and atmosphere during coastal drought events. A substantial fraction of the correlations are strongly negative $(\rho \leq-0.4 ; 23$ for SSTs and 15 for geopotential heights). One of the clearest examples of this is 1919, an El Niño year with significant negative height anomalies across the North Pacific, versus 2008, a strong La Niña with positive height anomalies across the midlatitudes in both hemispheres. We thus find no unified or even dominant set of ocean or atmosphere circulation patterns responsible for coastal droughts, demonstrating that they can arise from a variety of configurations in the ocean-atmosphere system.

For some years, the circulation anomalies in the OctoberMay composites appear contrary to what would be expected during coastal droughts. Droughts in 1919, 1924, 1966, and 


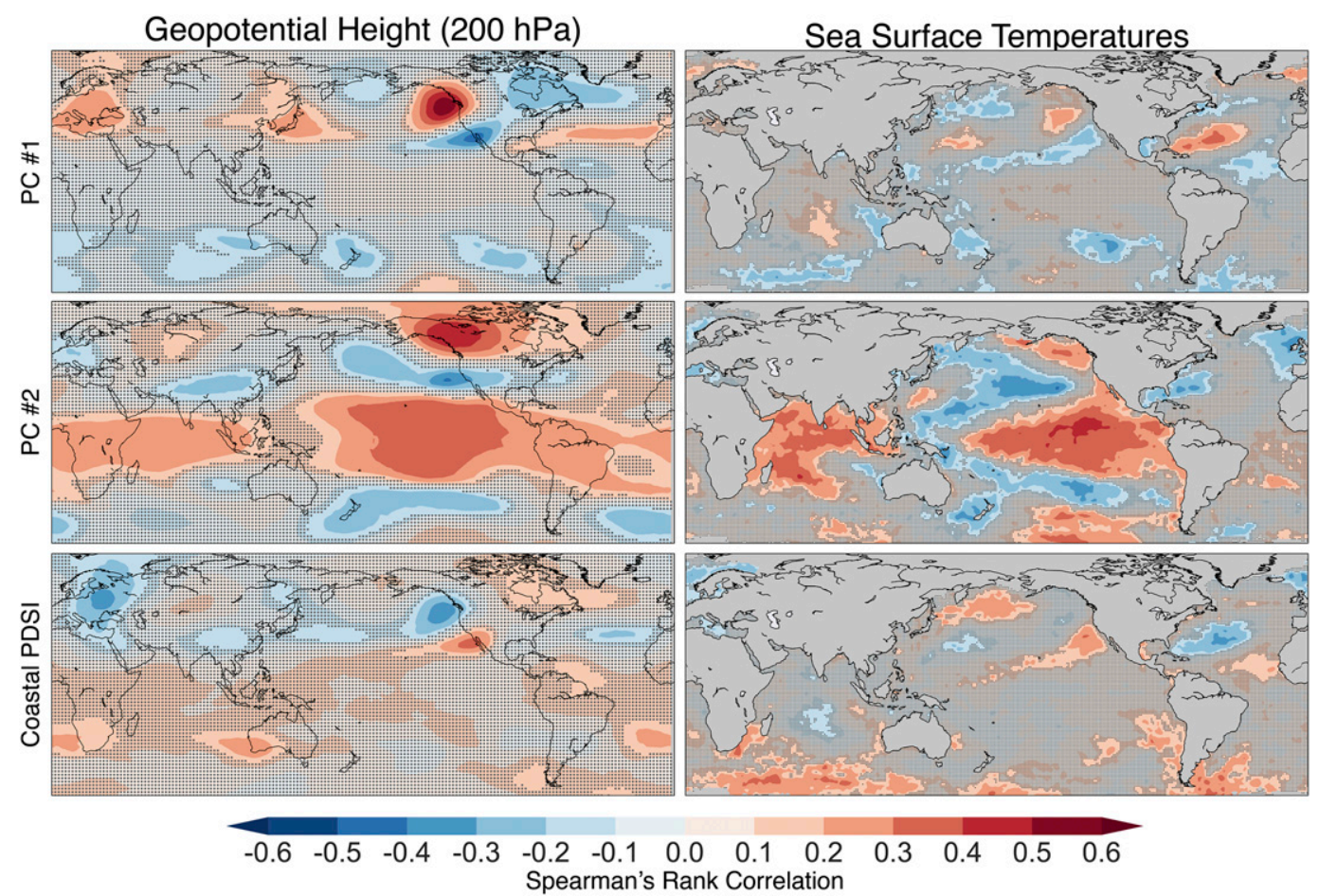

FIG. 10. Point-by-point correlations (Spearman's rank) for the ClimGrid PCs and coastal PDSI vs OctoberMarch (left) 200-hPa geopotential heights from the Twentieth Century Reanalysis (1896-2014) and (right) SSTs from HadISST (1896-2016). Insignificant correlations $(\rho>0.10)$ are stippled in gray.

1977 (three of them El Niño winters), for example, all show cyclonic circulation anomalies along or near the Pacific coast that would be expected to increase precipitation on the coast, rather than cause drought. Analyzing atmospheric circulation at a finer seasonal resolution (not shown), however, indicates that all these years have at least one period with anomalous ridging over the west: OND in 1977 and April-May in 1919, 1924, and 1966. These anomaly patterns are concealed in the extended October-May average and are consistent with results from the precipitation analysis, demonstrating that summer droughts can arise from precipitation deficits at varying times in the cold season. These findings also further reinforce the importance of internal atmospheric variability for coastal droughts, which is expected to be much more variable from month to month relative to circulation anomalies forced by persistent SSTs.

\section{f. Atmospheric rivers analysis}

Over the southern coast, PC1 correlates strongly and significantly ( $p \leq 0.001)$ with the number of landfalling AR days from October to March (Fig. 13, top), indicating that their frequency in this region is most strongly influenced by the precipitation mode connected to internal atmospheric variability. Correlations with PC2, by contrast, are weak and insignificant, suggesting little sensitivity to SST-forced storm-track shifts. There is also a strong tendency for fewer landfalling ARs over the southern coast during coastal drought events (brown dots in Fig. 13). The median number of landfalling AR events in the southern coastal region in this record (1948-2015) is 23 events per year, compared to a median of 19.5 events across the 10 coastal droughts in this period. This is consistent with previous analyses (Dettinger et al. 2011) that have demonstrated how moisture supplied by a few ARs can "make or break" a drought in this region.

In the northern coastal region (Fig. 13, bottom), however, the frequency of landfalling ARs is not significantly correlated with PC1, and there is no clear tendency for fewer landfalling ARs during coastal droughts. In this region, total precipitation is higher and the wet season is longer compared to the southern coast. Total cold-season precipitation and subsequent soil moisture availability may therefore be less sensitive to moisture contributions from individual ARs. The frequency of landfalling ARs in the northern coastal region, however, is significantly $(p \leq 0.001)$ correlated with PC2 and the precipitation dipole. This correlation is much weaker compared to landfalling ARs in the southern coastal region and PC1, but it 


\section{October-May 200hPa GPH and SST Anomalies}
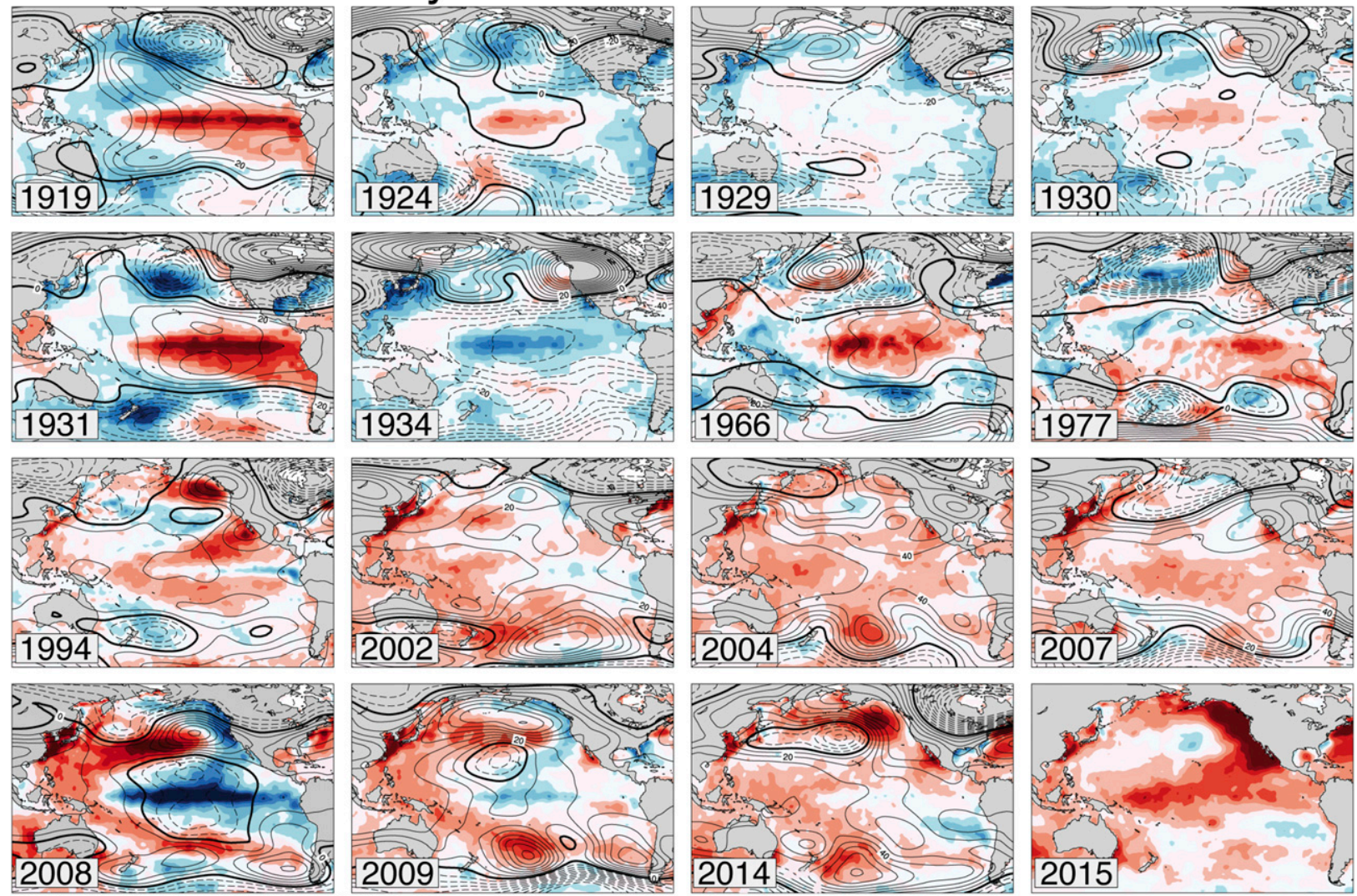

CONTOUR FROM -100 TO 100 BY $10[\mathrm{~m}]$

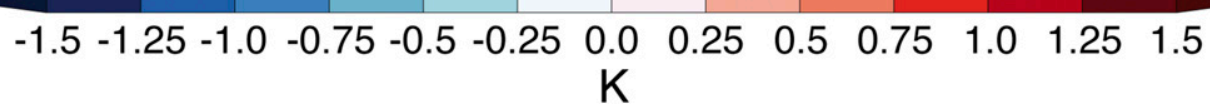

FIG. 11. For each coastal drought event, October-May average anomalies in 200-hPa geopotential height (contours, m) and SSTs (shading, K). Because the Twentieth Century Reanalysis ends in 2014, height anomalies for the 2015 event were not available.

suggests some sensitivity of northern coast AR frequency to SST-forced precipitation variability.

\section{Conclusions}

The dominance of internal atmospheric variability over the SST-forced dipole for hydroclimate along the Pacific coast has been well understood for years (Cayan and Roads 1984; McGuirk 1982), and this perspective holds in our analysis of coastal droughts. Investigating precipitation variability through the lens of the dipole and the associated ENSO-PDO teleconnections is appealing, nevertheless. These dynamics are well characterized and understood, and because of their connection to SSTs there is strong potential for seasonal (and possibly longer) predictability. Indeed, in regions where precipitation and drought variability are dominated by ENSO (e.g., the southwestern United States), the dipole and the state of ENSO provide important skill for seasonal forecasts. For much of the west, however, and the Pacific coast in particular, a comprehensive understanding of drought variability and risk requires moving beyond this dipole framework.

Widespread coastal drought events occur as a consequence of anomalous ridging near western North America or the northeast Pacific, deflecting storms and suppressing precipitation along the entire CONUS Pacific coast. These circulation patterns, and the associated precipitation anomalies, arise primarily from internal atmospheric variability, and this is reflected in the lack of congruence across events in the seasonal timing of the precipitation deficits and the underlying atmospheric dynamics. Notably, these droughts are strongly linked to a dearth of landfalling ARs south of $40^{\circ} \mathrm{N}$, where they are highly correlated with precipitation PC1 and internal atmospheric variability. In 


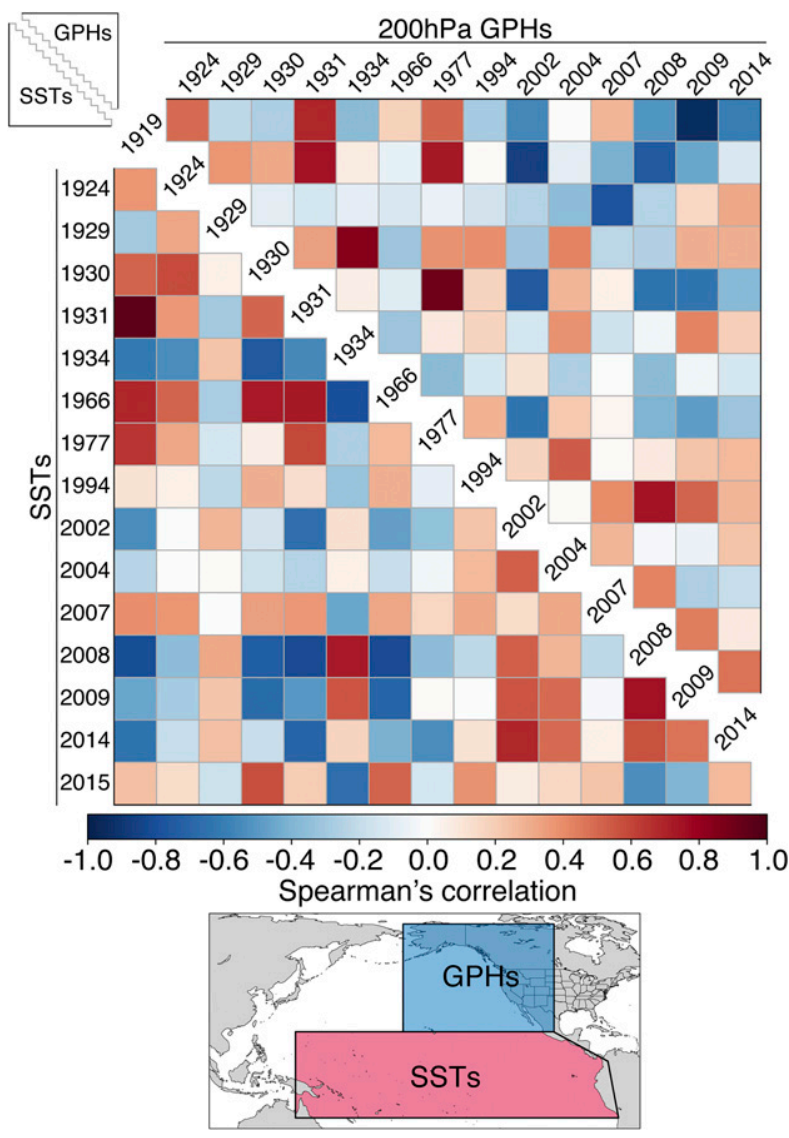

FIG. 12. (top) Pairwise uncentered pattern correlations between October-May anomalies in SSTs (lower left) and 200-hPa geopotential heights (upper right) for all coastal drought years. Strong positive correlations indicate similar spatial patterns in either geopotential height anomalies (GPHs; e.g., 1931 vs 1977) or SSTs (e.g., 1919 vs 1931) between two coastal drought years. (bottom) Spatial domains used to calculate the pattern correlations.

the northern coastal region, however, variability in the frequency of landfalling ARs does not contribute substantially to coastal droughts, and it shows a modest connection to the SST-forced dipole precipitation mode (PC2).

Despite the clear importance of atmospheric variability, which may be expected to have little interannual or decadal persistence, coastal droughts are not evenly distributed in time, and they show some apparent clustering in the 1920s and 1930s and in the early twenty-first century. These decades corresponded to extended periods of below-average moisture availability along the entire Pacific coast (Figs. 2 and 7), suggesting that there may be some source of low-frequency variability modulating drought in this region on decadal time scales. Typically, such memory or persistence would be expected to originate from decadal ocean dynamics, and the most likely source for this in the western CONUS is the PDO (McCabe et al. 2004). As noted previously, however, there is little consistency in the magnitude or even phasing of the PDO across the main two drought clusters, and, furthermore, it is well established that PDO teleconnections actually favor out-of-phase moisture anomalies in the meridional direction (McCabe et al. 2004). Warm conditions in the tropical Atlantic (e.g., a positive phase of the AMO) can also act to suppress precipitation across western North America (McCabe et al. 2004; Nigam et al. 2011), with the strongest influence during the fall (Nigam et al. 2011). Positive values of the AMO are associated with positive height anomalies during this season along the entire CONUS Pacific coast (Fig. 3a in Nigam et al. 2011), and so they potentially favor widespread coastal droughts. The AMO during fall (October-December) was positive during the 1930s $(+0.164)$ and the post-2000 $(+0.192)$ period of enhanced coastal dryness, but it was near neutral $(-0.097)$ during the arid 1920s. Any connection between Atlantic SSTs and coastal drought variability is therefore highly speculative at this stage. If the apparent clustering of coastal droughts is a robust feature of Pacific coast hydroclimate, however, there may be potential to constrain the risks of coastal drought occurrence on these decadal and longer time scales, if the source of low-frequency variability can be identified.

Our analyses have focused primarily on precipitation variability and the associated dynamics, the main drivers of historical droughts (e.g., Seager et al. 2015). Recent evidence suggests, however, that temperature impacts on evaporative demand and snow are playing an increasingly important role in drought dynamics in the western CONUS (e.g., Berg and Hall 2017; Diffenbaugh et al. 2015; Griffin and Anchukaitis 2014; Mote et al. 2016; Williams et al. 2015). For example, the Pacific Northwest in 2015 (the most recent coastal drought year) experienced a record-breaking snow drought, caused by near-normal total precipitation but record warmth that resulted in a much-diminished snowpack (Fosu et al. 2016; Mote et al. 2016). Snow cover was also exceptionally low that same year over the Sierra Nevada as a result of a combination of high temperatures and low precipitation (Harpold et al. 2017). Warming from climate change is expected to play an increasingly important role in future drought dynamics (e.g., Cook et al. 2015) and the associated impacts, such as wildfire (Abatzoglou and Williams 2016). Accurately assessing the risk and likelihood of coastal droughts in the future may therefore require more explicit consideration of the impact of warming temperatures on relevant processes, and the extent to which this warming may interact with precipitation variability to intensify moisture deficits. 


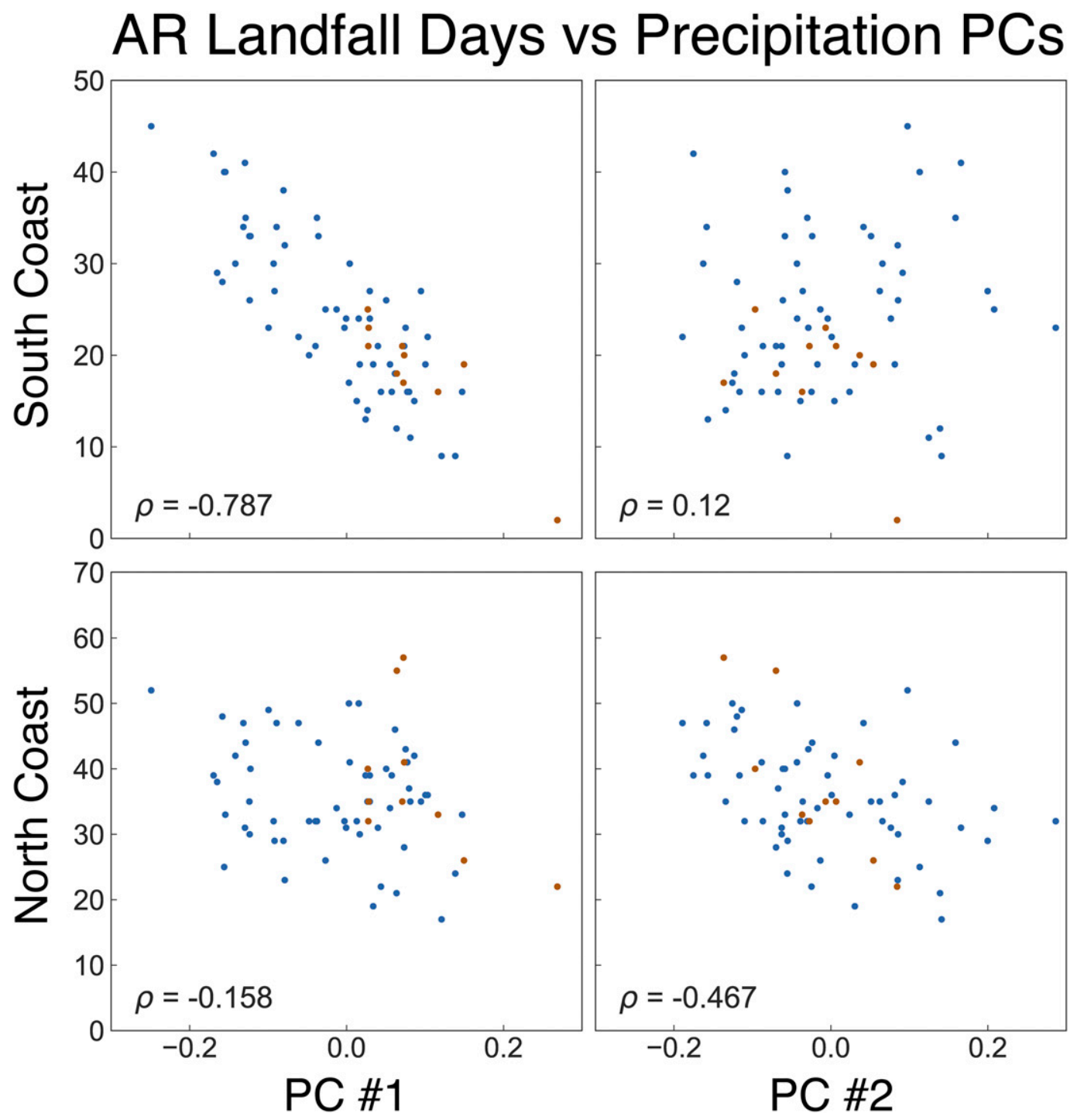

FIG. 13. Correlations between AR landfalling days (October-March) in the southern and northern coastal regions and the ClimGrid precipitation PCs. The AR record extends from 1948 to 2015; coastal droughts occurring during this period $(1966,1977,1994,2002,2004,2007,2008,2009,2014$, and 2015) are indicated with brown dots.

Acknowledgments. B. I. Cook was supported by NASA and the NASA Modeling, Analysis, and Prediction Program. J. S. Mankin was supported in part by an Earth Institute Postdoctoral Fellowship, and D. Singh was supported by the Lamont-Doherty Postdoctoral Fellowship in Earth and Environmental Science. R. Seager, J. S. Mankin, and J. E. Smerdon were supported in part by NSF Grants AGS-1243204 and AGS-1401400. R. Seager was additionally supported by NOAA Award NA14OAR4310232. A. P. Williams was supported in part by NSF AGS-1703029 and by the Center for Climate and Life at Columbia University. The AR database is made available by Bin Guan and obtained online (at https://ucla.box.com/ARcatalog).
The Lamont-Doherty Earth Observatory contribution number is 8161 .

\section{REFERENCES}

Abatzoglou, J. T., and A. P. Williams, 2016: Impact of anthropogenic climate change on wildfire across western US forests. Proc. Natl. Acad. Sci. USA, 113, 11770-11775, doi:10.1073/ pnas.1607171113.

Allen, R. G., L. S. Pereira, D. Raes, and M. Smith, 1998: Crop evapotranspiration-Guidelines for computing crop water requirements. FAO Irrigation and Drainage Paper 56, 15 pp., https://appgeodb.nancy.inra.fr/biljou/pdf/Allen_FAO1998.pdf.

Bao, J.-W., S. A. Michelson, P. J. Neiman, F. M. Ralph, and J. M. Wilczak, 2006: Interpretation of enhanced integrated water 
vapor bands associated with extratropical cyclones: Their formation and connection to tropical moisture. Mon. Wea. Rev., 134, 1063-1080, doi:10.1175/MWR3123.1.

Berg, N., and A. Hall, 2017: Anthropogenic warming impacts on California snowpack during drought. Geophys. Res. Lett., 44, 2511-2518, doi:10.1002/2016GL072104.

Bond, N. A., M. F. Cronin, H. Freeland, and N. Mantua, 2015: Causes and impacts of the 2014 warm anomaly in the NE Pacific. Geophys. Res. Lett., 42, 3414-3420, doi:10.1002/ 2015 GL063306.

Brown, D. P., and A. C. Comrie, 2004: A winter precipitation 'dipole' in the western United States associated with multidecadal ENSO variability. Geophys. Res. Lett., 31, L09203, doi:10.1029/2003GL018726.

Cayan, D. R., and J. O. Roads, 1984: Local relationships between United States West Coast precipitation and monthly mean circulation parameters. Mon. Wea. Rev., 112, 1276-1282, doi:10.1175/1520-0493(1984)112<1276: LRBUSW $>2.0$.CO;2.

— atmospheric circulation on streamflow in the west. Aspects of Climate Variability in the Pacific and Western Americas, D. H. Peterson, Ed., Amer. Geophys. Union, 375-397, doi:10.1029/ GM055p0375.

—, M. D. Dettinger, K. T. Redmond, G. J. McCabe, N. Knowles, and D. H. Peterson, 2003: The transboundary setting of California's water and hydropower systems. Climate and Water: Transboundary Challenges in the America, H. F. Diaz and B. J. Morehouse, Eds., Springer, 237-262, doi:10.1007/ 978-94-015-1250-3_11.

Coats, S., J. E. Smerdon, B. I. Cook, and R. Seager, 2015: Are simulated megadroughts in the North American Southwest forced? J. Climate, 28, 124-142, doi:10.1175/ JCLI-D-14-00071.1.

Cole, J. E., and E. R. Cook, 1998: The changing relationship between ENSO variability and moisture balance in the continental United States. Geophys. Res. Lett., 25, 4529-4532, doi:10.1029/1998GL900145.

Compo, G. P., and Coauthors, 2011: The Twentieth Century Reanalysis Project. Quart. J. Roy. Meteor. Soc., 137, 1-28, doi:10.1002/qj.776.

Cook, B. I., J. E. Smerdon, R. Seager, and S. Coats, 2014: Global warming and 21st century drying. Climate Dyn., 43, 2607-2627, doi:10.1007/s00382-014-2075-y.

_ , T. R. Ault, and J. E. Smerdon, 2015: Unprecedented 21st century drought risk in the American Southwest and Central Plains. Sci. Adv., 1, e1400082, doi:10.1126/sciadv.1400082.

Cook, E. R., C. A. Woodhouse, C. M. Eakin, D. M. Meko, and D. W. Stahle, 2004: Long-term aridity changes in the western United States. Science, 306, 1015-1018, doi:10.1126/ science. 1102586

Dai, A., 2013: Increasing drought under global warming in observations and models. Nat. Climate Change, 3, 52-58, doi:10.1038/nclimate1633; Erratum, 3, 171, doi:10.1038/ nclimate1811.

Daly, C., M. Halbleib, J. I. Smith, W. P. Gibson, M. K. Doggett, G. H. Taylor, J. Curtis, and P. P. Pasteris, 2008: Physiographically sensitive mapping of climatological temperature and precipitation across the conterminous United States. Int. J. Climatol., 28, 2031-2064, doi:10.1002/joc.1688.

Daniels, J., 2016: California drought costs to top $\$ 600$ million. CNBC, http://www.cnbc.com/2016/08/15/california-droughtcosts-to-top-600-million-dollars.html.
Davis, R. E., 1976: Predictability of sea surface temperature and sea level pressure anomalies over the North Pacific Ocean. J. Phys. Oceanogr., 6, 249-266, doi:10.1175/1520-0485(1976)006<0249: POSSTA $>2.0 . \mathrm{CO} ; 2$.

Delworth, T. L., F. Zeng, A. Rosati, G. A. Vecchi, and A. T. Wittenberg, 2015: A link between the hiatus in global warming and North American drought. J. Climate, 28, 3834-3845, doi:10.1175/JCLI-D-14-00616.1.

Dettinger, M. D., 2004: Fifty-two years of "pineapple-express" storms across the West Coast of North America. Scripps Institution of Oceanography for the California Energy Commission Tech. Rep. CEC-500-2005-004, 15 pp., http:// www.energy.ca.gov/2005publications/CEC-500-2005-004/CEC500-2005-004.PDF.

_ 2013: Atmospheric rivers as drought busters on the U.S. West Coast. J. Hydrometeor., 14, 1721-1732, doi:10.1175/ JHM-D-13-02.1.

, D. R. Cayan, H. F. Diaz, and D. M. Meko, 1998: North-south precipitation patterns in western North America on interannual-to-decadal timescales. J. Climate, 11, 3095-3111, doi:10.1175/1520-0442(1998)011<3095:NSPPIW>2.0.CO;2.

, F. M. Ralph, T. Das, P. J. Neiman, and D. R. Cayan, 2011: Atmospheric rivers, floods and the water resources of California. Water, 3, 445-478, doi:10.3390/w3020445.

Diaz, H. F., M. P. Hoerling, and J. K. Eischeid, 2001: ENSO variability, teleconnections and climate change. Int. J. Climatol., 21, 1845-1862, doi:10.1002/joc.631.

Dickie, G., 2016: 2015 wildfires burned a record-breaking 10.1 million acres. High Country News, http://www.hcn.org/ articles/wildfires-burned-a-record-breaking-10-1-millionacres-in-2015.

Diffenbaugh, N. S., D. L. Swain, and D. Touma, 2015: Anthropogenic warming has increased drought risk in California. Proc. Natl. Acad. Sci. USA, 112, 3931-3936, doi:10.1073/ pnas.1422385112.

Enfield, D. B., A. M. Mestas-Nuñez, and P. J. Trimble, 2001: The Atlantic multidecadal oscillation and its relation to rainfall and river flows in the continental U.S. Geophys. Res. Lett., 28 , 2077-2080, doi:10.1029/2000GL012745.

Feng, S., M. Trnka, M. Hayes, and Y. Zhang, 2017: Why do different drought indices show distinct future drought risk outcomes in the U.S. Great Plains? J. Climate, 30, 265-278, doi:10.1175/JCLI-D-15-0590.1.

Fosu, B. O., S.-Y. S. Wang, and J.-H. Yoon, 2016: The 2014/15 snowpack drought in Washington State and its climate forcing. Bull. Amer. Meteor. Soc., 97 (Suppl.), S19-S24, doi:10.1175/ BAMS-D-16-0154.1.

Fuchs, B., 2015: U.S. drought monitor, July 7, 2015. National Drought Mitigation Center, University of NebraskaLincoln, http://digitalcommons.unl.edu/cgi/viewcontent.cgi? article $=1154 \&$ context $=$ droughtarchive .

Gimeno, L., R. Nieto, M. Vázquez, and D. A. Lavers, 2014: Atmospheric rivers: A mini-review. Front. Earth Sci., 2, 2, doi:10.3389/feart.2014.00002.

Griffin, D., and K. J. Anchukaitis, 2014: How unusual is the 20122014 California drought? Geophys. Res. Lett., 41, 9017-9023, doi:10.1002/2014GL062433.

Guan, B., and D. E. Waliser, 2015: Detection of atmospheric rivers: Evaluation and application of an algorithm for global studies. J. Geophys. Res. Atmos., 120, 12514-12535, doi:10.1002/ $2015 J D 024257$. 
Harpold, A. A., M. Dettinger, and S. Rajagopal, 2017: Defining snow drought and why it matters. Eos, Trans. Amer. Geophys. Union, 98, doi:10.1029/2017EO068775.

Hartmann, D. L., 2015: Pacific sea surface temperature and the winter of 2014. Geophys. Res. Lett., 42, 1894-1902, doi:10.1002/2015GL063083.

He, M., M. Russo, and M. Anderson, 2017: Hydroclimatic characteristics of the 2012-2015 California drought from an operational perspective. Climate, 5, 5, doi:10.3390/cli5010005.

Jenkins, D., 2017: WSDA estimates '15 drought damage topped $\$ 700$ million. Capital Press, http://www.capitalpress.com/ Washington/20170216/wsda-estimates-15-drought-damagetopped-700-million.

Jong, B.-T., M. Ting, and R. Seager, 2016: El Niño's impact on California precipitation: Seasonality, regionality, and El Niño intensity. Environ. Res. Lett., 11, 054021, doi:10.1088/ 1748-9326/11/5/054021.

Kahn, B., 2016: The 2015 wildfire season set an ominous record. Climate Central, http://www.climatecentral.org/news/2015wildfire-season-sets-ominous-record-19879.

Kintisch, E., 2016: How a "Godzilla" El Niño shook up weather forecasts. Science, 352, 1501-1502, doi:10.1126/ science.352.6293.1501

Klein, W. H., 1957: Principal tracks and mean frequencies of cyclones and anti-cyclones in the Northern Hemisphere. U.S. Weather Bureau Research Paper 40, 53 pp.

Lee, M.-Y., C.-C. Hong, and H.-H. Hsu, 2015: Compounding effects of warm sea surface temperature and reduced sea ice on the extreme circulation over the extratropical North Pacific and North America during the 2013-2014 boreal winter. Geophys. Res. Lett., 42, 1612-1618, doi:10.1002/2014GL062956.

Lurie, J., 2015: The drought isn't just a California problem. Mother Jones, http://www.motherjones.com/environment/2015/08/ drought-isnt-just-california-problem.

Malevich, S. B., and C. A. Woodhouse, 2017: Pacific sea surface temperatures, midlatitude atmospheric circulation, and widespread interannual anomalies in western U.S. streamflow. Geophys. Res. Lett., 44, 5123-5132, doi:10.1002/ 2017GL073536.

McAfee, S. A., 2014: Consistency and the lack thereof in Pacific decadal oscillation impacts on North American winter climate. J. Climate, 27, 7410-7431, doi:10.1175/ JCLI-D-14-00143.1.

, and E. K. Wise, 2016: Intra-seasonal and inter-decadal variability in ENSO impacts on the Pacific Northwest. Int. J. Climatol., 36, 508-516, doi:10.1002/joc.4351.

McCabe, G. J., and M. D. Dettinger, 2002: Primary modes and predictability of year-to-year snowpack variations in the western United States from teleconnections with Pacific Ocean climate. J. Hydrometeor., 3, 13-25, doi:10.1175/ 1525-7541(2002)003<0013:PMAPOY > 2.0.CO;2.

- M. A. Palecki, and J. L. Betancourt, 2004: Pacific and Atlantic Ocean influences on multidecadal drought frequency in the United States. Proc. Natl. Acad. Sci. USA, 101, 4136-4141, doi:10.1073/pnas.0306738101.

McGuirk, J. P., 1982: A century of precipitation variability along the Pacific coast of North America and its impact. Climatic Change, 4, 41-56, doi:10.1007/BF00143191.

Meko, D. M., and C. W. Stockton, 1984: Secular variations in streamflow in the western United States. J. Climate Appl. Meteor., 23, 889-897, doi:10.1175/1520-0450(1984)023<0889: SVISIT $>2.0 . \mathrm{CO} ; 2$.
Mirchi, A., K. Madani, M. Roos, and D. W. Watkins, 2013: Climate change impacts on California's water resources. Drought in Arid and Semi-Arid Regions, K. Schwabe et al., Eds., Springer, 301-319, doi:10.1007/978-94-007-6636-5_17.

Mitchell, K. E., and Coauthors, 2004: The multi-institution North American Land Data Assimilation System (NLDAS): Utilizing multiple GCIP products and partners in a continental distributed hydrological modeling system. J. Geophys. Res. 109, D07S90, doi:10.1029/2003JD003823.

Monteith, J. L., 1965: Evaporation and environment. Symp. Soc. Exp. Biol., 19, 205-234.

Mote, P. W., and Coauthors, 2016: Perspectives on the causes of exceptionally low 2015 snowpack in the western United States. Geophys. Res. Lett., 43, 10 980-10 988, doi:10.1002/ 2016GL069965.

Nigam, S., B. Guan, and A. Ruiz-Barradas, 2011: Key role of the Atlantic multidecadal oscillation in 20th century drought and wet periods over the Great Plains. Geophys. Res. Lett., 38, L16713, doi:10.1029/2011GL048650.

Oyler, J. W., A. Ballantyne, K. Jencso, M. Sweet, and S. W. Running, 2015: Creating a topoclimatic daily air temperature dataset for the conterminous United States using homogenized station data and remotely sensed land skin temperature. Int. J. Climatol., 35, 2258-2279, doi:10.1002/ joc. 4127.

Palmer, W. C., 1965: Meteorological drought. U.S. Weather Bureau Research Paper 45, 58 pp., http://www.ncdc.noaa.gov/ temp-and-precip/drought/docs/palmer.pdf.

Piechota, T. C., and J. A. Dracup, 1996: Drought and regional hydrologic variation in the United States: Associations with the El Niño-Southern Oscillation. Water Resour. Res., 32 1359-1373, doi:10.1029/96WR00353.

Rayner, N. A., D. E. Parker, E. B. Horton, C. K. Folland, L. V. Alexander, D. P. Rowell, E. C. Kent, and A. Kaplan, 2003: Global analyses of sea surface temperature, sea ice, and night marine air temperature since the late nineteenth century. J. Geophys. Res., 108, 4407, doi:10.1029/2002JD002670.

Redmond, K. T., and R. W. Koch, 1991: Surface climate and streamflow variability in the western United States and their relationship to large-scale circulation indices. Water Resour. Res., 27, 2381-2399, doi:10.1029/91WR00690.

Rice, D., 2015: California drought cost is 2.7 billion in 2015. USA Today, http://www.usatoday.com/story/weather/2015/08/19/ california-drought-cost-27-billion-2015/32007967/.

Rodell, M., and Coauthors, 2004: The Global Land Data Assimilation System. Bull. Amer. Meteor. Soc., 85, 381-394, doi:10.1175/BAMS-85-3-381.

Roman, J., 2015: The year in wildfire. NFPA Journal, http://www. nfpa.org/news-and-research/publications/nfpa-journal/2015/ november-december-2015/features/the-year-in-wildfire.

Rutz, J. J., W. J. Steenburgh, and F. M. Ralph, 2014: Climatological characteristics of atmospheric rivers and their inland penetration over the western United States. Mon. Wea. Rev., 142, 905-921, doi:10.1175/MWR-D-13-00168.1.

Schneider, U., A. Becker, P. Finger, A. Meyer-Christoffer, M. Ziese, and B. Rudolf, 2014: GPCC's new land surface precipitation climatology based on quality-controlled in situ data and its role in quantifying the global water cycle. Theor. Appl. Climatol., 115, 15-40, doi:10.1007/ s00704-013-0860-x.

,,$---\frac{-}{-}$, B. Rudolf, and M. Ziese, 2015: GPCC full data reanalysis version $7.0\left(\right.$ at $\left.0.5^{\circ}, 1.0^{\circ}, 2.5^{\circ}\right)$ : Monthly landsurface precipitation from rain-gauges built on GTS-based 
and historic data. NOAA National Climatic Data Center, accessed 1 November 2017, doi:10.5676/DWD_GPCC/ FD_M_V7_050.

Schubert, S. D., M. J. Suarez, P. J. Pegion, R. D. Koster, and J. T. Bacmeister, 2004: On the cause of the 1930s Dust Bowl. Science, 303, 1855-1859, doi:10.1126/science.1095048.

Seager, R., and G. A. Vecchi, 2010: Greenhouse warming and the 21st century hydroclimate of southwestern North America. Proc. Natl. Acad. Sci. USA, 107, 21 277-21282, doi:10.1073/ pnas.0910856107.

, and M. Hoerling, 2014: Atmosphere and ocean origins of North American droughts. J. Climate, 27, 4581-4606, doi:10.1175/JCLI-D-13-00329.1.

- - - S. Schubert, H. Wang, B. Lyon, A. Kumar, J. Nakamura, and N. Henderson, 2015: Causes and predictability of the 2011-2014 California drought. NOAA Drought Task Force, 40 pp., http://cpo.noaa.gov/Portals/0/ Docs/MAPP/TaskForces/DTF/california_drought_report.pdf.

Seneviratne, S. I., T. Corti, E. L. Davin, M. Hirschi, E. B. Jaeger, I. Lehner, B. Orlowsky, and A. J. Teuling, 2010: Investigating soil moisture-climate interactions in a changing climate: A review. Earth Sci. Rev., 99, 125-161, doi:10.1016/ j.earscirev.2010.02.004.

Sheffield, J., G. Goteti, and E. F. Wood, 2006: Development of a 50-year high-resolution global dataset of meteorological forcings for land surface modeling. J. Climate, 19, 3088-3111, doi:10.1175/JCLI3790.1.

Singh, D., D. L. Swain, J. S. Mankin, D. E. Horton, L. N. Thomas, B. Rajaratnam, and N. S. Diffenbaugh, 2016: Recent amplification of the North American winter temperature dipole. J. Geophys. Res. Atmos., 121, 9911-9928, doi:10.1002/ 2016JD025116.

Swain, D. L., M. Tsiang, M. Haugen, D. Singh, A. Charland, B. Rajaratnam, and N. S. Diffenbaugh, 2014: The extraordinary California drought of 2013/2014: Character, context, and the role of climate change. Bull. Amer. Meteor. Soc., 95 (Suppl.), s3-s7, http://www2.ametsoc.org/ams/assets/File/ publications/BAMS_EEE_2013_Full_Report.pdf.

_ D. E. Horton, D. Singh, and N. S. Diffenbaugh, 2016: Trends in atmospheric patterns conducive to seasonal precipitation and temperature extremes in California. Sci. Adv., 2, e1501344, doi:10.1126/sciadv.1501344.

Trenberth, K. E., A. Dai, G. van der Schrier, P. D. Jones, J. Barichivich, K. R. Briffa, and J. Sheffield, 2014: Global warming and changes in drought. Nat. Climate Change, $\mathbf{4}, 17-$ 22, doi:10.1038/nclimate2067.

Vose, R. S., and Coauthors, 2014: Improved historical temperature and precipitation time series for U.S. climate divisions. J. Appl. Meteor. Climatol., 53, 1232-1251, doi:10.1175/JAMC-D-13-0248.1.

Wanders, N., and Coauthors, 2017: Forecasting the hydroclimatic signature of the 2015/16 El Niño event on the western United States. J. Hydrometeor., 18, 177-186, doi:10.1175/ JHM-D-16-0230.1.

Wang, S.-Y. S., W.-R. Huang, and J.-H. Yoon, 2015: The North American winter 'dipole' and extremes activity: A CMIP5 assessment. Atmos. Sci. Lett., 16, 338-345, doi:10.1002/ asl2.565.

, J.-H. Yoon, R. R. Gillies, and H.-H. Hsu, 2017: The California drought: Trends and impacts. Climate Extremes: Patterns and Mechanisms, S.-Y. S. Wang et al., Eds., John Wiley and Sons, 223-235, doi:10.1002/9781119068020.

Wells, N., S. Goddard, and M. J. Hayes, 2004: A self-calibrating Palmer Drought Severity Index. J. Climate, 17, 2335-2351, doi:10.1175/1520-0442(2004)017<2335:ASPDSI>2.0.CO;2.

Williams, A. P., R. Seager, J. T. Abatzoglou, B. I. Cook, J. E. Smerdon, and E. R. Cook, 2015: Contribution of anthropogenic warming to California drought during 2012-2014. Geophys. Res. Lett., 42, 6819-6828, doi:10.1002/2015GL064924.

Wise, E. K., 2010: Spatiotemporal variability of the precipitation dipole transition zone in the western United States. Geophys. Res. Lett., 37, L07706, doi:10.1029/2009GL042193.

_ 2016: Five centuries of U.S. West Coast drought: Occurrence, spatial distribution, and associated atmospheric circulation patterns. Geophys. Res. Lett., 43, 4539-4546, doi:10.1002/ 2016 GL068487.

Wolf, S., D. Yin, and M. L. Roderick, 2017: Using radiative signatures to diagnose the cause of warming during the 20132014 Californian drought. J. Hydrol., 553, 408-418, doi:10.1016/j.jhydrol.2017.07.015.

Woodhouse, C. A., J. L. Russell, and E. R. Cook, 2009: Two modes of North American drought from instrumental and paleoclimatic data. J. Climate, 22, 4336-4347, doi:10.1175/ 2009JCLI2705.1.

Yin, D., M. L. Roderick, G. Leech, F. Sun, and Y. Huang, 2014: The contribution of reduction in evaporative cooling to higher surface air temperatures during drought. Geophys. Res. Lett., 41, 7891-7897, doi:10.1002/2014GL062039. 